\title{
ON THE CONNEXION
}

\author{
BETWEEN THE
}

\section{HEAT OF THE BODY}

\author{
AND THE
}

\section{EXCRETED AMOUNTS OF UREA, CHLORIDE OF SODIUM, AND URINARY WATER,}

\author{
D U R I N G A F I T O F A G U E.
}

\author{
BY \\ SYDNEY RINGER, M.R.C.S., \\ LATE PHYSICIAN'S ASSISTANT IN UNIVERSITY COLLEGR HOSPITAC. \\ COMMUNICATED BY \\ RICHARD QUAIN, F.R.S.
}

Received June 6th-Read June 28th, 1859.

THe observations on the temperature of the body during ague fits are now numerous and accordant, ${ }^{2}$ and may be considered sufficient to indicate the general condition of the animal heat during the several stages of ague.

1 The following observations were made at the suggestion of Dr. Parkes, from whom, from time to time, I have received assistance. Dr. Parkes has also supplied the entire literature in the paper, and has kindly examined it with care.

2 Zimmermann ; Bärensprung, Müller's 'Archiv,' 1852, p. 217 ; Michael, 'Archiv für Phys. Heilk.,' 1856, p. 39; Wunderlich, 'Archiv für Phys. Heilk.,' 1858, p. 12. 
The increase in the amount of urea and of chloride of sodium during the cold and hot stages has been affirmed by Traube and Jochmann, ${ }^{1}$ Moos, ${ }^{2}$ Redenbacher, ${ }^{3}$ and Hammond. ${ }^{4}$ These observations have been criticised, however, and certainly some of the cases were not examined with any great minuteness. In no case yet reported either has any comparison been drawn between the rise in the temperature and the amount of the urea and chloride of sodium. ${ }^{5}$ It therefore seemed extremely desirable, on the occasion of a patient with ague being admitted into University College Hospital, under the care of Dr. Parkes, to examine the subject, and to see, first of all, whether the increase of urea and of chloride of sodium really occur in the cold and hot stages of ague, as affirmed hy Traube, Redenbacher, and Hammond; and, secondly, whether any close connexion could be traced between the amount of urea and the abnormal temperature. My position as one of the resident officers in the hospital at the time gave me the opportunity of carrying out the inquiry with all the minuteness necessary for accuracy.

The general results may be thus stated-that not only was the increase of urea and of chloride of sodium constant during the cold and hot stages of ague, but that their amount was in very close relation to the temperature. The first case recorded in this paper will, I believe, give little short of mathematical proof of the connexion between these two phenomena, viz., the increase of heat of body and of the excretion of urea and chloride of sodium.

The second case communicated is one in which the phenomena were less carefully observed, but it is valuable as affording another instance of the increase of urea and chloride of sodium during the fit.

1 'Deutsche Klinik,' No. 46, Nov., 1855.

2 Henle's 'Zeitschrift für rat. Med.,' Band vii, p. 291.

3 Henle's 'Zeitschrift,' Band ii (Dritte Reihe), p. 384.

4 'American Journal of Med. Science,' April, 1858.

5 Some other observations have been made on the excretions of twenty-four hours, but these are of little value as febrile and non-febrile bones are put together. 
In addition, a case of hectic fever occurring in phthisis has been narrated, for in this case the phenomena were found to be identical with those presented by malarial ague. The result was the same in both cases, although the causes were so different.

CASE 1. Quotidian ague.-The patient, a man, was first attacked by tertian in August last, whilst working at Maldon, in Essex. The ague continued on him for three weeks, by which time he was apparently cured; he remained working at the same place till the December following. At that time, moving up to London, he broke his leg, and was carried to Charing Cross Hospital. Upon being discharged from that institution, cured, he caught cold, and an attack of ague immediately followed, and has continued more or less since, being immediately brought on by exposure to cold. This long continuance produced the usual effects of prolonged ague; and in this state he was admitted into the hospital, the disease having changed a day or two previously from the tertian to the quotidian type.

He suffers from slight aortic obstructive disease. His pulse is continually about 120 per minute, ${ }^{1}$ exceedingly irregular in both force and rhythm. His arteries are very tortuous and visible. He never suffered from rheumatism, and has no arcus senilis. Except the above heart-disease, he suffers from no organic lesion.

$\mathrm{He}$ is fifty-nine years of age, but looks much older. His weight is 144 pounds; his height five feet nine and three quarter inches. His vital capacity (Hutchinson's spirometer) is 140 cubic inches.

The examination was conducted in the following manner. The patient was put to bed, and his urine collected through the night. At 5 a.m. he had breakfast, consisting of two eggs, bread and butter, and tea, the latter being measured. At 6 a.m. he was made to pass his urine, and all passed at

1 No tables are therefore given of the pulse. 
the time was mixed with that passed during the night. The thermometer (a good one, by Negretti and Zambra, and divided into fifths of a Fahrenheit degree) was rext placed in his axilla, and kept there during the remainder of the day, the temperature being noted down every quarter of an hour. He was also made to pass his urine hourly, or upon the commencement of another stage, before the completion of the hour, and the next hour was dated from that time; by this means we not only obtained the urine of every hour, but also of each stage, separately. The patient was allowed no food until the completion of the fit, when he had a good meat dinner and six ounces of wine. Lemonade he was permitted to drink ad libitum, but the quantity was always measured and noted, with the time at which it was taken. He was weighed immediately after his breakfast, and again at the termination of the fit, and during this time no motions were allowed to be passed. The patient was purposely kept without medicine. In determining the amount of urea and chloride of sodium, Liebig's volumetric method with nitrate of mercury was used.

It was not possible to determine the other urinary constituents in this case. The chloride of sodium was not got rid of before testing for urea, but the usual correction was made.

The following charts show the variations in the temperature in fifths of a degree, as taken every quarter of an hour. Above the table are two columns, one showing the amount of urea, the other the amount of chloride of sodium, poured out. The quantity per hour is stated in each case, and put down in the column denoting the time at which it was passed. It indicates, of course, the quantity formed during the previous hour. The amounts of urea and chloride of sodium are given always in French grammes, and the water in cubic centimetres. The commencement of each stage, as judged of in the usual way, by the sensations of the patient, is also noted in the column proper to the time at which it began.

For the purpose of greater clearness and of giving fuller 


\section{APRIL 6 TH}

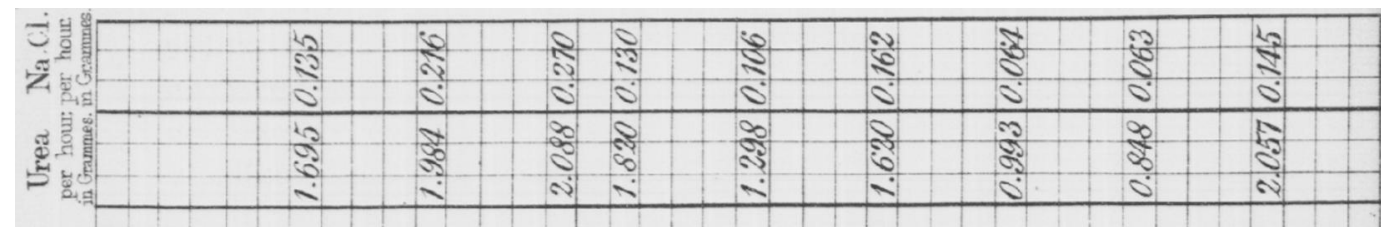

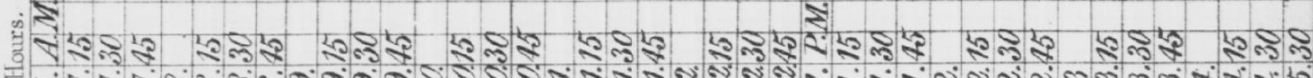

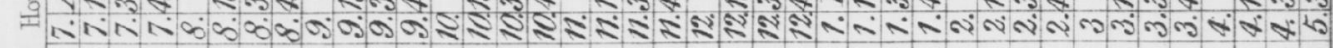
Temp? $105^{\circ}$

$4 / 5$

$3 / 5$

$3 / 5$

104
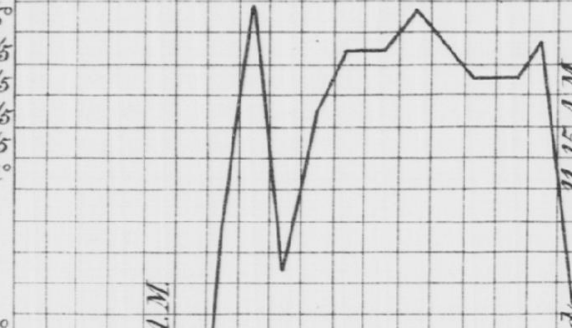

103

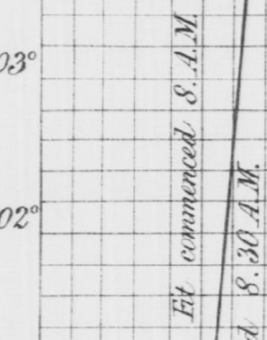

10

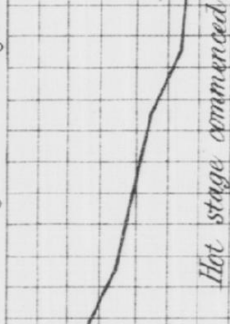

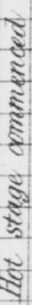

$99^{2}$

98

$4 / 5$

$97^{2} / 5$

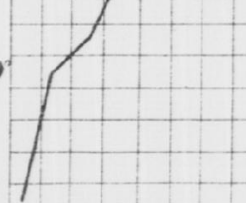

nomassis.
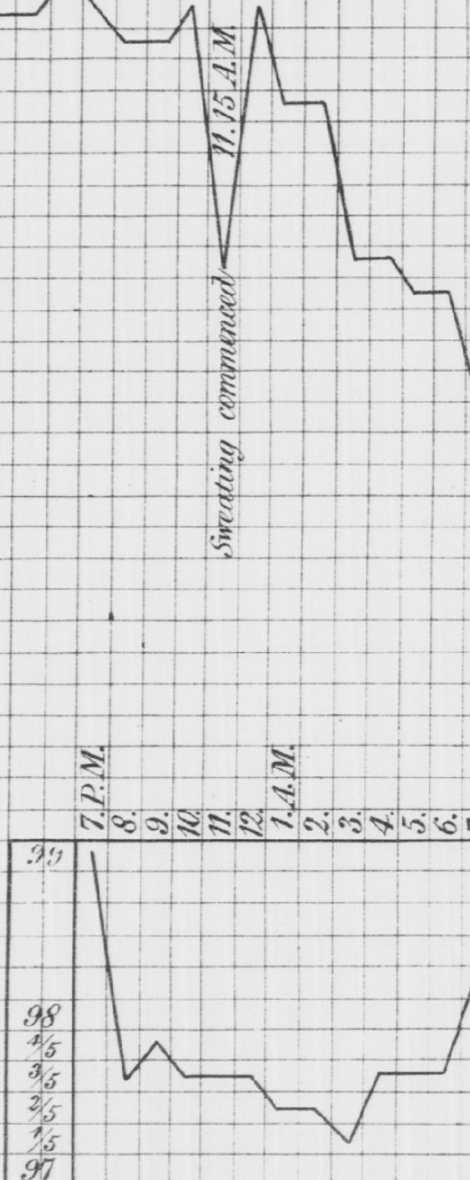

है
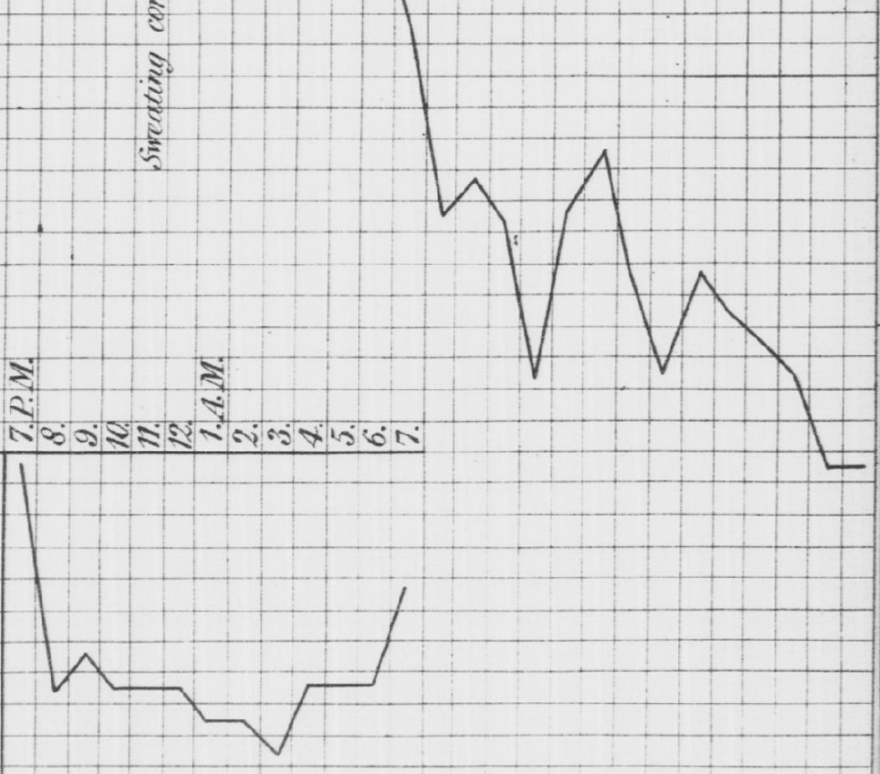


\section{APRIL 7 TH}

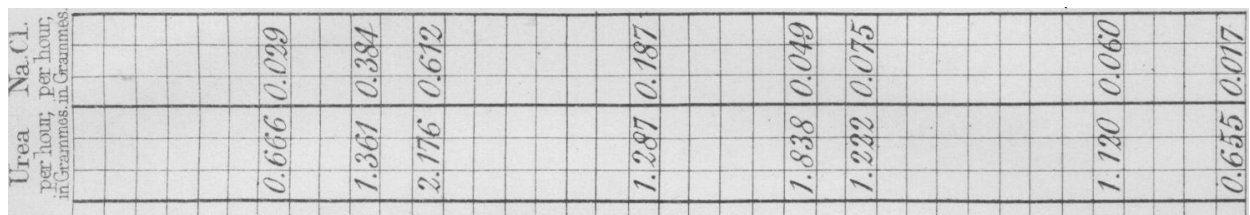

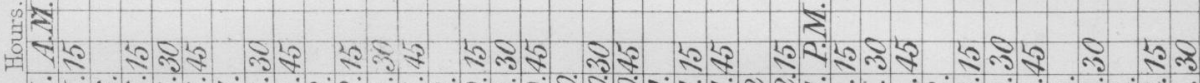

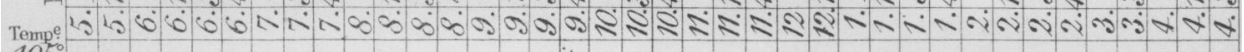

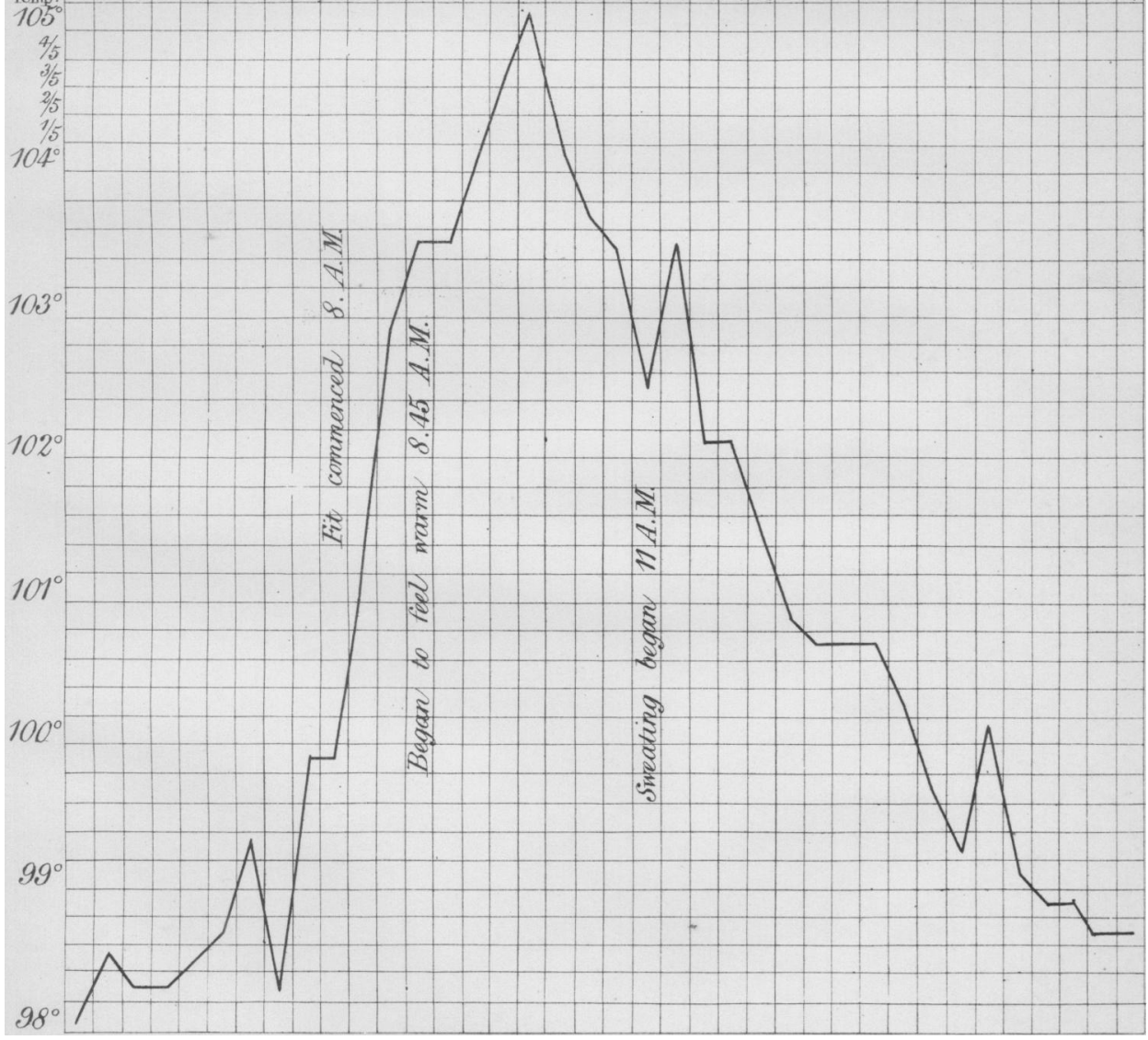




\section{APRIL $8^{\text {TH }}$}
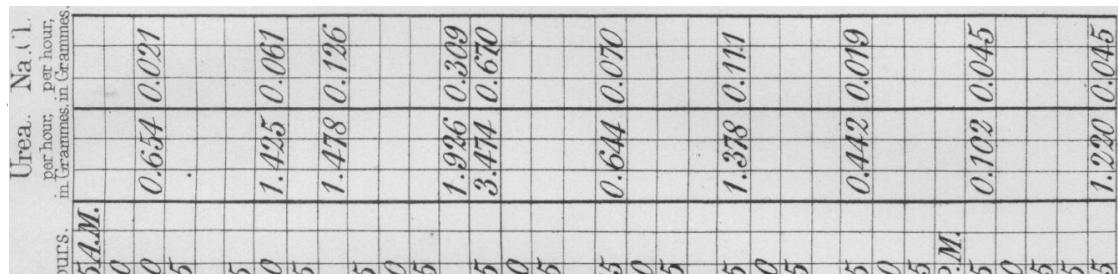

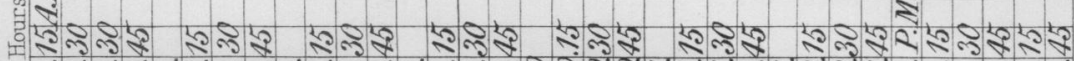

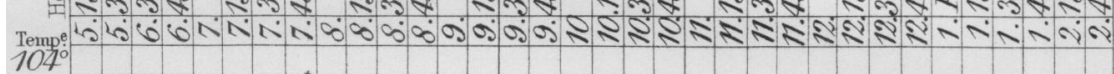

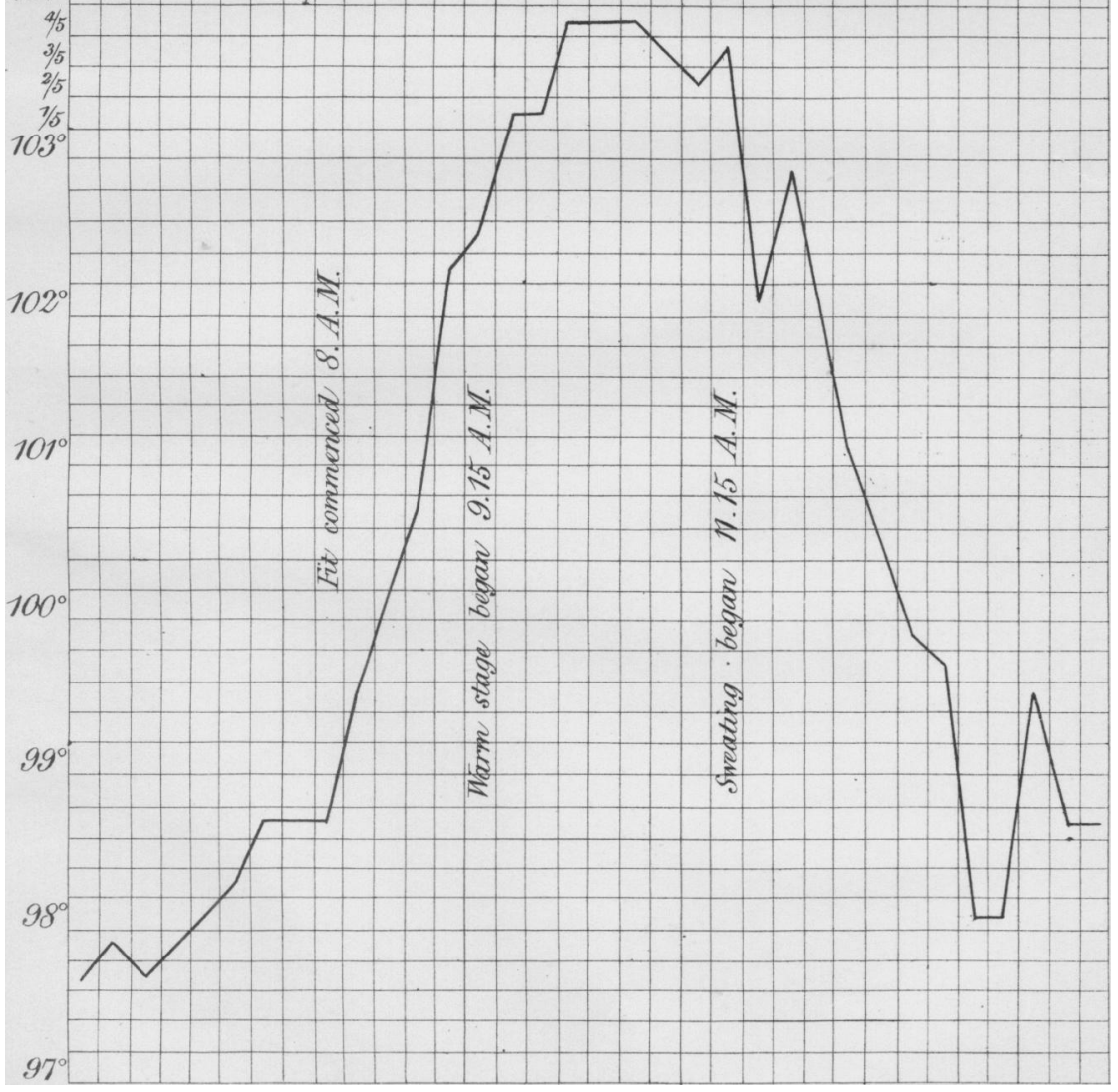




\section{APRIL $9^{\text {TH }}$}

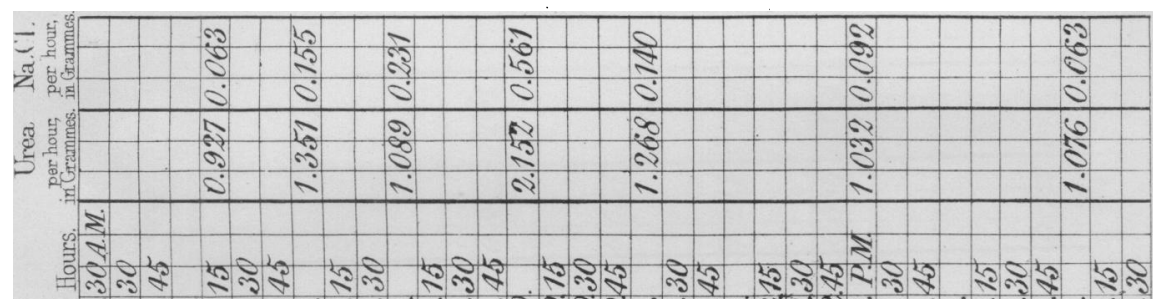

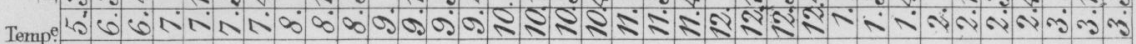

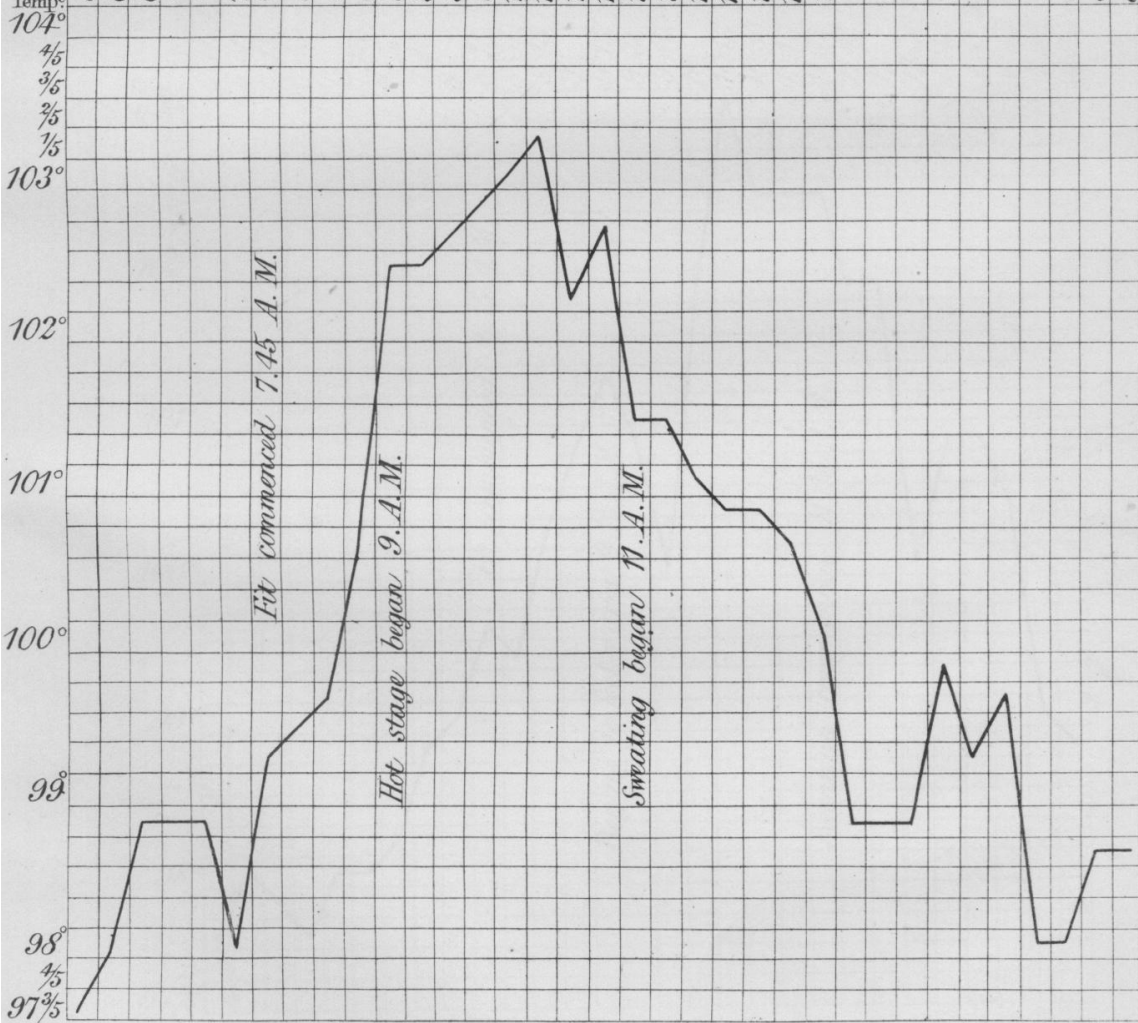

Wries: ath. 


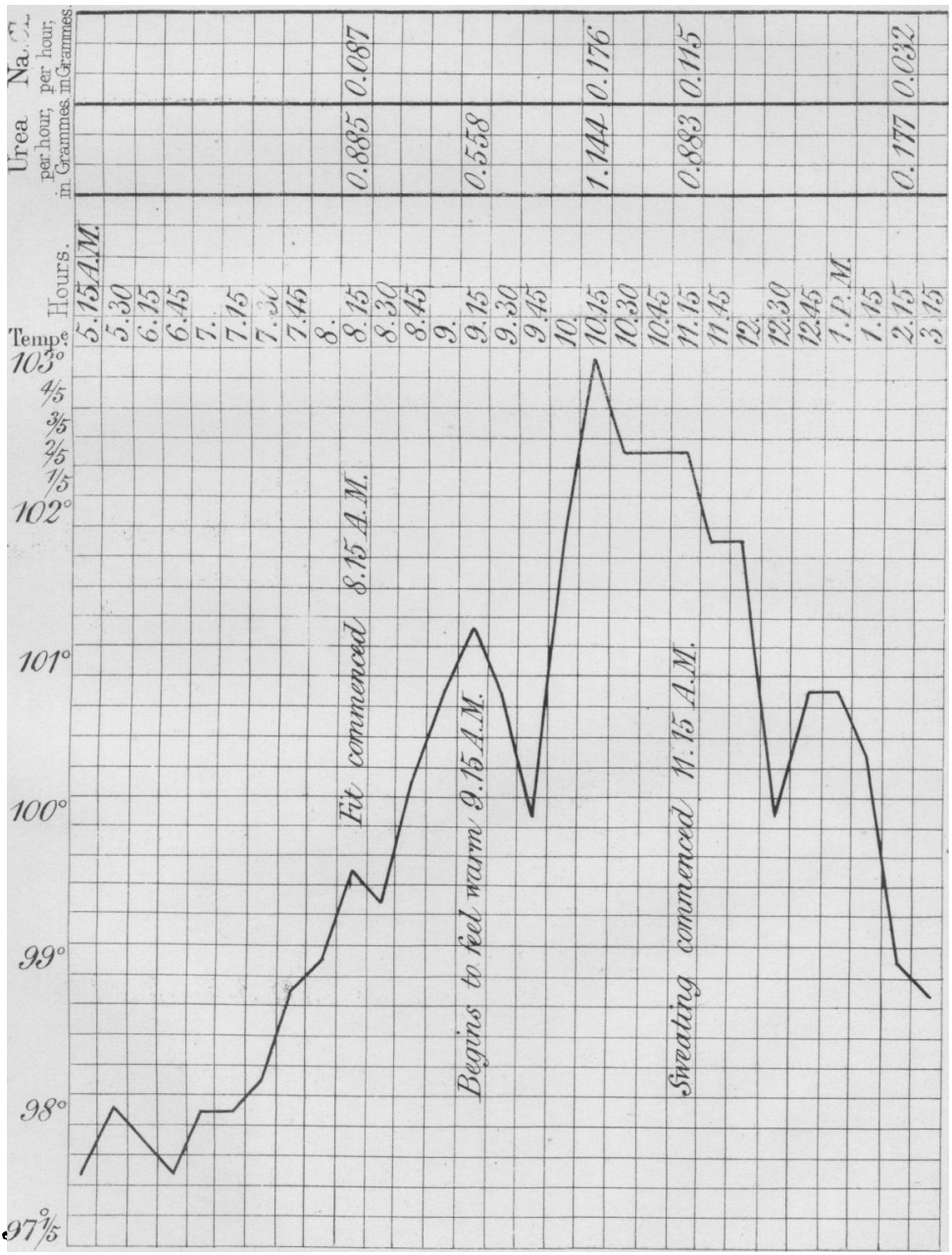




\section{APRIL $\|{ }^{\text {TH }}$}

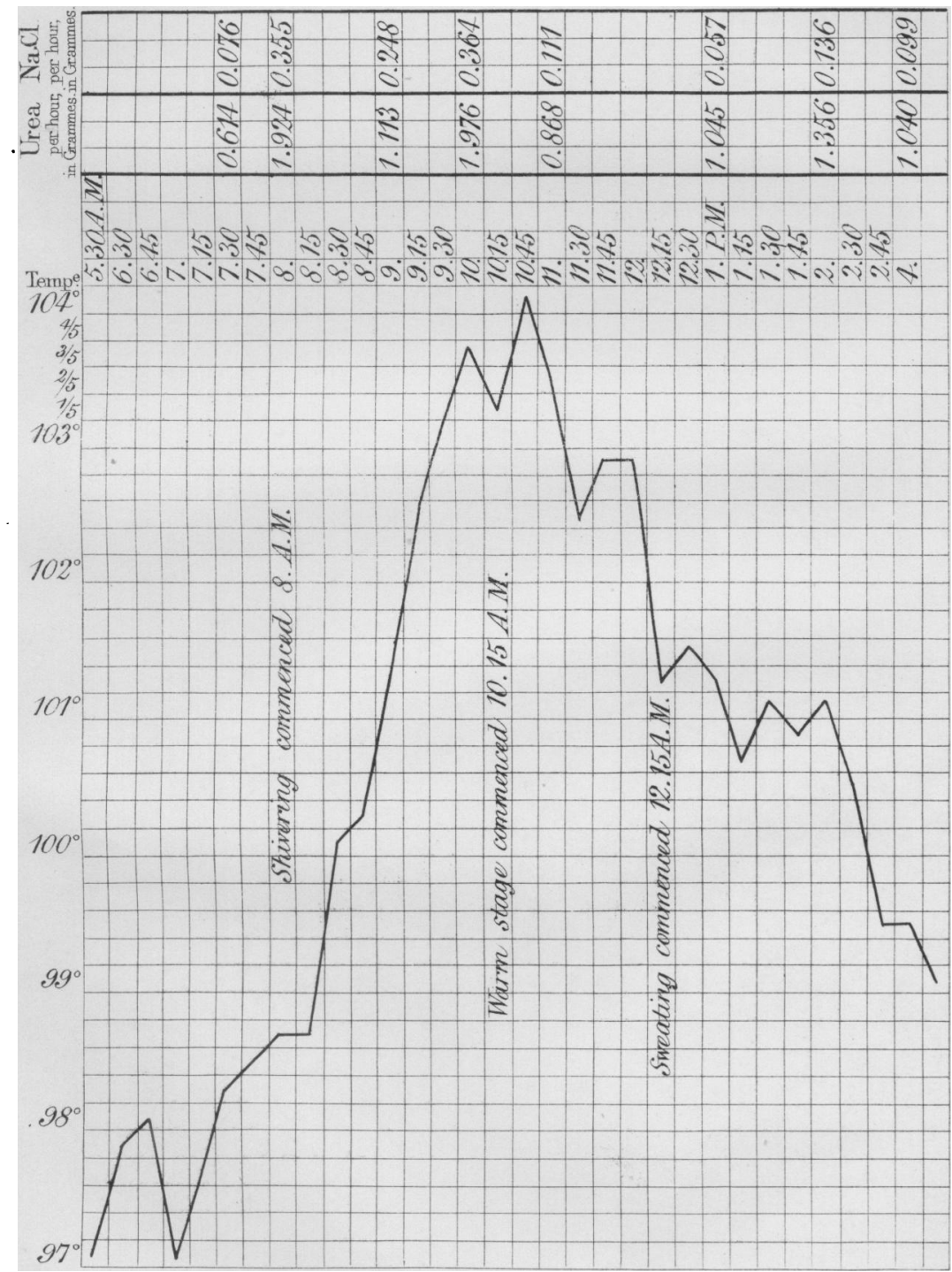


details, tables are added, recapitulating the amount of the urea, chloride of sodium, and water, separately. In the first column of each table the stages are written down; in the next the hour at which the urine was passed; then follows the total amount of urea contained in the urine passed during the specified time; the next column shows the amount reduced to hours; and, lastly, the average amount of each stage per hour is given.

TABLe.

APRIL 6th.-UREA.

\begin{tabular}{|c|c|c|c|c|}
\hline Stage. & Hour. & $\begin{array}{l}\text { Total Quantity } \\
\text { in this time. }\end{array}$ & $\begin{array}{l}\text { Quantity per } \\
\text { hour. }\end{array}$ & $\begin{array}{c}\text { Average Quantity } \\
\text { per hour during } \\
\text { period. }\end{array}$ \\
\hline $\begin{array}{l}\text { Cold } \ldots \ldots \ldots \ldots \\
\text { Hot } \ldots \ldots \ldots \ldots \ldots \\
\text { Sweating } \ldots \ldots \ldots\end{array}$ & $\begin{array}{l}7 \cdot 45 \text { to } 8 \cdot 30 \text { a.m. } \\
8.30 \text { to } 9 \cdot 30 \text { a.m. } \\
9 \cdot 30 \text { to } 10 \cdot 30 \text { a.m. } \\
10.30 \text { to } 11 \text { a.m. } \\
11 \text { to } 12 \text { a.m. } \\
12 \text { to } 1 \text { p.m. } \\
1 \text { to } 2 \text { p.m. } \\
2 \text { to } 3 \text { p.m. } \\
3 \text { to } 4 \text { p.m. }\end{array}$ & $\begin{array}{c}\text { Grammes. } \\
1.356 \\
1.984 \\
2.088 \\
0.910 \\
1.289 \\
1.620 \\
0.993 \\
0.848 \\
2.057\end{array}$ & $\begin{array}{c}\text { Grammes. } \\
1.695 \\
1.984 \\
2.088 \\
1.820 \\
1.289 \\
1.620 \\
0.993 \\
0.848 \\
2.057\end{array}$ & $\left\{\begin{array}{l}\begin{array}{l}\text { Grammes. } \\
1.695 \\
1.964 \\
1.363\end{array}\end{array}\right.$ \\
\hline \multicolumn{5}{|c|}{ CHLORIDE OF SODIUM. } \\
\hline $\begin{array}{l}\text { Cold } \ldots \ldots \ldots \ldots \\
\text { Hot } \ldots \ldots \ldots \ldots \\
\text { Sweating } \ldots \ldots . .\end{array}$ & \begin{tabular}{|l}
$7 \cdot 45$ to 8.30 a.m. \\
$8 \cdot 30$ to $9 \cdot 30$ a.m. \\
$9 \cdot 30$ to 10.30 a.m. \\
10.30 to 11 a.m. \\
11 to 12 a.m. \\
12 to 1 p.m. \\
1 to 2 p.m. \\
2 to 3 p.m. \\
3 to 4 p.m.
\end{tabular} & $\begin{array}{l}0 \cdot 108 \\
0 \cdot 216 \\
0 \cdot 270 \\
0 \cdot 065 \\
0 \cdot 106 \\
0 \cdot 162 \\
0 \cdot 064 \\
0 \cdot 063 \\
0 \cdot 145\end{array}$ & $\begin{array}{l}0 \cdot 135 \\
0 \cdot 216 \\
0 \cdot 270 \\
0 \cdot 130 \\
0 \cdot 106 \\
0 \cdot 162 \\
0 \cdot 064 \\
0 \cdot 063 \\
0 \cdot 145\end{array}$ & $\left\{\begin{array}{l}0.135 \\
0.220 \\
0.108\end{array}\right.$ \\
\hline \multicolumn{5}{|c|}{ WATER. } \\
\hline $\begin{array}{l}\text { Cold } \ldots \ldots \ldots \ldots \\
\text { Hot } \ldots \ldots \ldots \ldots . . . \\
\text { Sweating } \ldots \ldots . .\end{array}$ & \begin{tabular}{|}
745 to 8.30 a.m. \\
8.30 to $9 \cdot 30$ a.m. \\
$9 \cdot 30$ to 10.30 a.m. \\
10.30 to 11 a.m. \\
11 to 12 a.m. \\
12 to 1 p.m. \\
1 to 2 p.m. \\
2 to 3 p.m. \\
3 to 4 p.m.
\end{tabular} & $\begin{array}{r}75 \text { c.c. } \\
80 \text { c.c. } \\
90 \text { c.c. } \\
82 \text { c.c. } \\
59 \text { c.c. } \\
90 \text { c.c. } \\
54 \text { c.c. } \\
53 \text { c.c. } \\
121 \text { c.c. }\end{array}$ & & - \\
\hline
\end{tabular}


APRIL 7th.-UREA.

\begin{tabular}{|c|c|c|c|c|}
\hline Stage. & Hour. & $\begin{array}{l}\text { Total Quantity } \\
\text { in this time. }\end{array}$ & $\begin{array}{l}\text { Quantity per } \\
\text { hour. }\end{array}$ & $\begin{array}{l}\text { Average Quantity } \\
\text { per hour during } \\
\text { period. }\end{array}$ \\
\hline 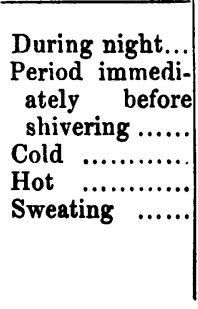 & \begin{tabular}{|}
3 p.m. to $5 \cdot 30$ a.m. \\
5.30 to 7 a.m. \\
7 to 8 a.m. \\
8 to 8.30 a.m. \\
$8 \cdot 30$ to $10 \cdot 30$ a.m. \\
11 to 12 a.m. \\
12 to 1 p.m. \\
1 to 3 p.m. \\
3 to 5 p.m.
\end{tabular} & $\begin{array}{c}\text { Grammes. } \\
10 \cdot 272 \\
0.999 \\
\\
1 \cdot 361 \\
1 \cdot 088 \\
2 \cdot 575 \\
0.838 \\
1 \cdot 222 \\
2 \cdot 240 \\
1 \cdot 311\end{array}$ & $\begin{array}{c}\text { Grammes. } \\
0.684 \\
0.666 \\
\\
1 \cdot 361 \\
2 \cdot 176 \\
1 \cdot 287 \\
0 \cdot 838 \\
1 \cdot 222 \\
1 \cdot 120 \\
0.655\end{array}$ & $\begin{array}{l}\text { Grammes. } \\
0 \cdot 684 \\
0 \cdot 666 \\
\\
1 \cdot 361 \\
2 \cdot 176 \\
1 \cdot 287 \\
\\
0.935\end{array}$ \\
\hline \multicolumn{5}{|c|}{ CHLORIDE OF SODIUM. } \\
\hline 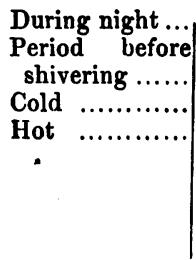 & \begin{tabular}{|}
3 p.m. to 5.30 a.m. \\
$5 \cdot 30$ to 7 a.m. \\
7 to 8 a.m. \\
8 to $8 \cdot 30$ a.m. \\
$8 \cdot 30$ to 10.30 a.m. \\
11 to 12 a.m. \\
12 to 1 p.m. \\
1 to 3 p.m. \\
3 to 5 p.m.
\end{tabular} & $\begin{array}{l}0 \cdot 642 \\
0 \cdot 440 \\
0 \cdot 384 \\
0 \cdot 306 \\
0 \cdot 375 \\
0 \cdot 049 \\
0 \cdot 075 \\
0 \cdot 120 \\
0 \cdot 034\end{array}$ & $\begin{array}{l}0.029 \\
0.29 \\
0.384 \\
0.612 \\
0.187 \\
0.049 \\
0.075 \\
0.060 \\
0.017\end{array}$ & $\begin{array}{l}0.029 \\
0.29 \\
0.381 \\
0.612 \\
0 \cdot 187 \\
\\
0.064\end{array}$ \\
\hline \multicolumn{5}{|c|}{ QUANTITY OF URINE PASSED. } \\
\hline $\begin{array}{l}\text { Beforeshivering } \\
\text { Cold } \ldots \ldots \ldots \ldots . . . \\
\text { Hot } \ldots \ldots \ldots \ldots . . \\
\\
\end{array}$ & $\mid \begin{array}{l}3 \text { p.m. to } 5 \cdot 30 \text { a.m. } \\
5 \cdot 30 \text { to } 7 \text { a.m. } \\
7 \text { to } 8 \text { a.m. } \\
8 \text { to } 8 \cdot 30 \text { a.m. } \\
8 \cdot 30 \text { to } 10 \cdot 30 \text { a.m. } \\
11 \text { to } 12 \text { a.m. } \\
12 \text { to } 1 \text { p.m. } \\
1 \text { to } 3 \text { p.m. } \\
3 \text { to } 5 \text { p.m. }\end{array}$ & $\begin{array}{l}36 \text { c.c. } \\
25 \text { c.c. } \\
80 \text { c.c. } \\
136 \text { c.c. } \\
62 \text { c.c. } \\
33 \text { c.c. } \\
50 \text { c.c. } \\
50 \text { c.c. } \\
28 \text { c.c. }\end{array}$ & . & \\
\hline \multicolumn{5}{|c|}{ APRIL 8th.-UREA. } \\
\hline 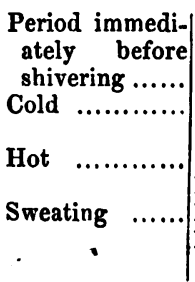 & \begin{tabular}{|}
5 p.m. to 6.30 a.m. \\
6.30 to $7 \cdot 30$ a.m. \\
7.30 to 8 a.m. \\
8 to 9 a.m. \\
9 to $9 \cdot 15$ a.m. \\
$9 \cdot 15$ to $10 \cdot 15$ a.m. \\
$10 \cdot 15$ to $11 \cdot 15$ a.m. \\
$11 \cdot 15$ to 12.15 p.m. \\
12.15 to $1 \cdot 15$ p.m. \\
$1 \cdot 15$ to $2 \cdot 45$ p.m.
\end{tabular} & $\begin{array}{l}8 \cdot 832 \\
1 \cdot 425 \\
0 \cdot 738 \\
1 \cdot 926 \\
0 \cdot 868 \\
0 \cdot 644 \\
1 \cdot 378 \\
0 \cdot 044 \\
0 \cdot 102 \\
1 \cdot 830\end{array}$ & $\begin{array}{l}0.654 \\
1.425 \\
1.478 \\
1.926 \\
3 \cdot 474 \\
0.644 \\
1.378 \\
0.044 \\
0 \cdot 102 \\
1.220\end{array}$ & $\left\{\begin{array}{l}0.654 \\
1.452 \\
2.700 \\
1.011 \\
0.498\end{array}\right.$ \\
\hline
\end{tabular}


URINARY EXCRETIONS IN AGUE.

CHLORIDE OF SODIUM.

\begin{tabular}{|c|c|c|c|c|}
\hline Stage. & Hour. & $\begin{array}{l}\text { Total Quantity } \\
\text { in this time. }\end{array}$ & $\begin{array}{l}\text { Quantity per } \\
\text { hour. }\end{array}$ & $\begin{array}{l}\text { Average Quantity } \\
\text { per hour during } \\
\text { period. }\end{array}$ \\
\hline 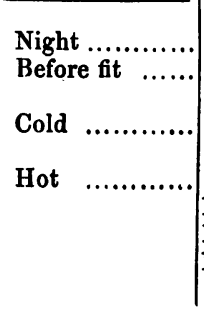 & \begin{tabular}{|}
5 p.m.to 6.30 a.m. \\
$6 \cdot 30$ to $7 \cdot 30$ a.m. \\
$7 \cdot 30$ to 8 a.m. \\
8 to 9 a.m. \\
9 to $9 \cdot 15$ a.m. \\
$9 \cdot 15$ to $10 \cdot 15$ a.m. \\
$10 \cdot 15$ to $11 \cdot 15$ a.m. \\
$11 \cdot 15$ to $12 \cdot 15$ p.m. \\
$12 \cdot 15$ to $1 \cdot 15$ p.m. \\
$1 \cdot 15$ to $2 \cdot 45$ p.m.
\end{tabular} & $\begin{array}{l}\text { Grammes. } \\
0.576 \\
0.064 \\
0.063 \\
0.309 \\
0.167 \\
0.070 \\
0.111 \\
0.019 \\
0.045 \\
0.045\end{array}$ & $\begin{array}{l}\text { Grammes. } \\
0.021 \\
0.064 \\
0.162 \\
0.309 \\
0.670 \\
0.070 \\
0.111 \\
0.019 \\
0.045 \\
0.030\end{array}$ & $\left\{\begin{array}{l}\text { Grammes. } \\
0.021 \\
0.095 \\
0.381 \\
0.090 \\
0.027\end{array}\right.$ \\
\hline $\begin{array}{l}\text { Night ............ } \\
\text { Before fit } \ldots \ldots . . \\
\text { Cold } \ldots \ldots \ldots \ldots . . . \\
\text { Hot } \ldots \ldots \ldots \ldots \ldots \\
\end{array}$ & $\begin{array}{l}\text { QUANTITY } 0 \\
\begin{array}{|l|}5 \text { p.m. to } 6.30 \text { a.m. } \\
6 \cdot 30 \text { to } 7 \cdot 30 \text { a.m. } \\
7 \cdot 30 \text { to } 8 \text { a.m. } \\
8 \text { to } 9 \text { a.m. } \\
9 \text { to } 9 \cdot 15 \text { a.m. } \\
9 \cdot 15 \text { to } 10 \cdot 15 \text { a.m. } \\
10 \cdot 15 \text { to } 11 \cdot 15 \text { a.m. } \\
11 \cdot 15 \text { to } 12 \cdot 15 \text { p.m. } \\
12 \cdot 15 \text { to } 1 \cdot 15 \text { p.m. } \\
1 \cdot 15 \text { to } 2 \cdot 45 \text { p.m. }\end{array}\end{array}$ & \begin{tabular}{|c|} 
F URINE PA \\
42 c.c. \\
54 c.c. \\
60 c.c. \\
86 c.c. \\
172 c.c. \\
26 c.c. \\
52 c.c. \\
13 c.c. \\
38 c.c. \\
50 c.c.
\end{tabular} & SSED. & • \\
\hline \multicolumn{5}{|c|}{ APRIL 9TH.-UREA. } \\
\hline 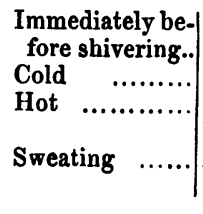 & \begin{tabular}{|l}
$6 \cdot 15$ to $7 \cdot 15$ a.m. \\
$7 \cdot 15$ to 8 a.m. \\
8 to 9 a.m. \\
9 to 10 a.m. \\
10 to 11 a.m. \\
11 to 1 p.m. \\
1 to 3 p.m.
\end{tabular} & $\begin{array}{l}0 \cdot 927 \\
1 \cdot 081 \\
1 \cdot 089 \\
2 \cdot 152 \\
1 \cdot 268 \\
2 \cdot 164 \\
2 \cdot 353\end{array}$ & $\begin{array}{l}0.927 \\
1 \cdot 351 \\
1 \cdot 089 \\
2 \cdot 152 \\
1.268 \\
1 \cdot 032 \\
1 \cdot 076\end{array}$ & $\begin{array}{l}0.927 \\
1.351 \\
1 \cdot 089 \\
1 \cdot 710 \\
1 \cdot 129\end{array}$ \\
\hline \multicolumn{5}{|c|}{ CHLORIDE OF SODIUM. } \\
\hline 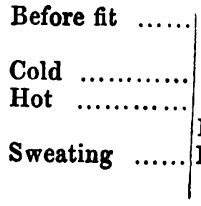 & $\left|\begin{array}{l}6 \cdot 15 \text { to } 7 \cdot 15 \text { a.m. } \\
7 \cdot 15 \text { to } 8 \text { a.m. } \\
8 \text { to } 9 \text { a.m. } \\
9 \text { to } 10 \text { a.m. } \\
10 \text { to } 11 \text { a.m. } \\
11 \text { to } 1 \text { p.m. } \\
1 \text { to } 3 \text { p.m. }\end{array}\right|$ & \begin{tabular}{l|}
$0 \cdot 063$ \\
$0 \cdot 124$ \\
$0 \cdot 231$ \\
$0 \cdot 561$ \\
$0 \cdot 140$ \\
$0 \cdot 184$ \\
$0 \cdot 127$
\end{tabular} & $\begin{array}{l}0 \cdot 063 \\
0 \cdot 155 \\
0 \cdot 231 \\
0 \cdot 561 \\
0 \cdot 140 \\
0 \cdot 092 \\
0 \cdot 063\end{array}$ & $\left\{\begin{array}{l}0.063 \\
0.155 \\
0.231 \\
0.351 \\
0.078\end{array}\right.$ \\
\hline \multicolumn{5}{|c|}{ QUANTITY OF URINE PASSED. } \\
\hline $\begin{array}{l}\text { Before fit ....... } \\
\text { Cold } \ldots \ldots \ldots \ldots \ldots \\
1 \\
1\end{array}$ & $\left|\begin{array}{l}6 \cdot 15 \text { to } 7 \cdot 15 \text { a.m. } \\
7 \cdot 15 \text { to } 8 \text { a.m. } \\
8 \text { to } 9 \text { a.m. } \\
9 \text { to } 10 \text { a.m. } \\
10 \text { to } 11 \text { a.m. } \\
11 \text { to } 1 \text { p.m. } \\
1 \text { to } 3 \text { p.m. }\end{array}\right|$ & 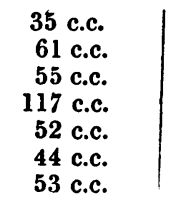 & & \\
\hline
\end{tabular}


APRIL 10TH.-UREA.

\begin{tabular}{|c|c|c|c|c|}
\hline Stage. & - Hour. & $\begin{array}{l}\text { Total Quantity } \\
\text { in this time. }\end{array}$ & $\begin{array}{l}\text { Quantity per } \\
\text { hour. }\end{array}$ & $\begin{array}{c}\text { Average Quantit } \\
\text { per hour during } \\
\text { period. }\end{array}$ \\
\hline $\begin{array}{l}\text { Before fit } \ldots \ldots . \\
\text { Cold } \ldots \ldots \ldots \ldots \ldots \\
\text { Hot } \ldots \ldots \ldots \ldots \ldots \\
\\
\text { Sweating } \quad \ldots \ldots .\end{array}$ & $\begin{array}{r}6 \cdot 30 \text { to } 8 \cdot 15 \text { a.m. } \\
8 \cdot 15 \text { to } 9 \cdot 15 \text { a.m. } \\
9 \cdot 15 \text { to } 10 \cdot 15 \text { a.m. } \\
10 \cdot 15 \text { to } 11 \cdot 15 \text { a.m. } \\
11 \cdot 15 \text { to } 2 \cdot 15 \text { p.m. }\end{array}$ & $\begin{array}{c}\text { Grammes. } \\
1 \cdot 420 \\
0.558 \\
1 \cdot 144 \\
0.883 \\
0.532\end{array}$ & $\begin{array}{l}\text { Grammes. } \\
0.885 \\
0.558 \\
1 \cdot 144 \\
0 \cdot 883 \\
0 \cdot 177\end{array}$ & $\begin{array}{c}\text { Grammes. } \\
0.885 \\
0.558 \\
1.013 \\
0.177\end{array}$ \\
\hline
\end{tabular}

CHLORIDE OF SODIUM.

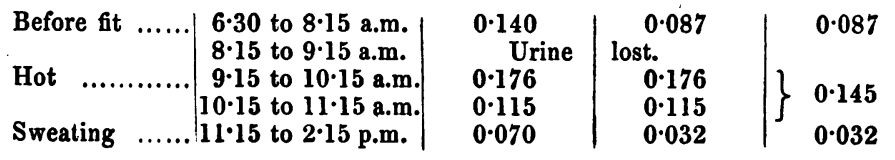

QUANTITY OF URINE PASSED.

\begin{tabular}{|c|c|}
\hline $\begin{array}{l}\text { Before fit } \ldots \ldots \\
\text { Cold } \quad \ldots \ldots \ldots \ldots \\
\text { Hot } \ldots \ldots \ldots \ldots .\end{array}$ & $\left|\begin{array}{c}6 \cdot 30 \text { to } 8 \cdot 15 \mathrm{a} . \mathrm{m} . \\
8 \cdot 15 \text { to } 9 \cdot 15 \mathrm{a} . \mathrm{m} . \\
9 \cdot 15 \text { to } 10 \cdot 15 \mathrm{a} . \mathrm{m} . \\
10 \cdot 15 \text { to } 11 \cdot 15 \mathrm{a.m} . \\
11 \cdot 15 \text { to } 2 \cdot 15 \mathrm{p.m} .\end{array}\right|$ \\
\hline
\end{tabular}

APRIL 11TH.-UREA.

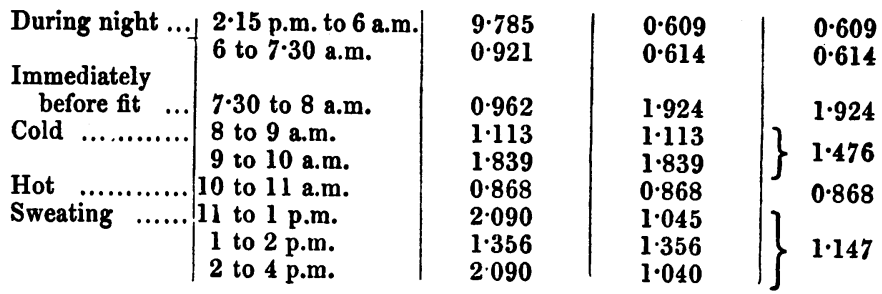

CHLORIDE OF SODIUM.

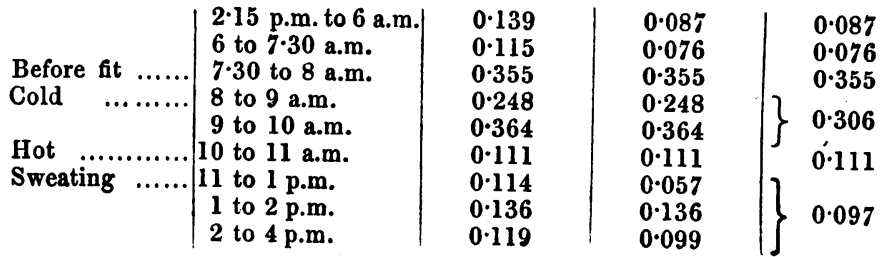


URINARY EXCRETIONS IN AGUE.

QUANTITY OF URINE PASSED.

\begin{tabular}{|c|c|c|}
\hline Stage. & Hour. & $\begin{array}{l}\text { Total Quantity } \\
\text { in this time. }\end{array}$ \\
\hline $\begin{array}{l}\text { Night } \ldots \ldots \ldots \ldots \\
\text { Before fit } \ldots \ldots \ldots \\
\text { Cold } \ldots \ldots \ldots \ldots \ldots \\
\text { Hot } \ldots \ldots \ldots \ldots \ldots\end{array}$ & $\begin{array}{l}2 \cdot 15 \text { p.m. to } 6 \text { a.m. } \\
6 \text { to } 7 \cdot 30 \text { a.m. } \\
7 \cdot 30 \text { to } 8 \text { a.m. } \\
8 \text { to } 9 \text { a.m. } \\
9 \text { to } 10 \text { a.m. } \\
10 \text { to } 11 \text { a.m. } \\
11 \text { to } 1 \text { p.m. } \\
1 \text { to } 2 \text { p.m. } \\
2 \text { to } 4 \text { p.m. }\end{array}$ & $\begin{array}{l}24 \text { c.c. } \\
74 \text { c.c. } \\
64 \text { c.c. } \\
76 \text { c.c. } \\
31 \text { c.c. } \\
38 \text { c.c. } \\
57 \text { c.c. } \\
95 \text { c.c. }\end{array}$ \\
\hline
\end{tabular}

Conclusions from the previous Facts.

\section{Temperature.}

The temperature during the several fits, amid much general resemblance, presented numerous partial differences, all of which are, however, reducible to order.

(a) In every case, the temperature commenced to rise previous to the cold stage, ${ }^{1}$ as experienced by the patient, that is to say, before any feeling of cold or illness of any kind. The time that it commenced, previous to the cold stage, varied from an hour and a half to three quarters of an hour, and no connexion between the time and the severity of the fit could be traced. The temperature commenced to rise-

April 6th. .11 hour before any feeling of cold or illness.

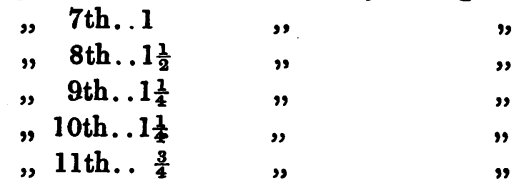

A close connexion between the severity of the fit and the character of the rise before the cold stage existed, the severity being in proportion to the continuousness of the rise, and also to the extent of each rise. As the fit became less severe, the temperature had a tendency either to oscillate, rise slowly, or remain stationary, and these tendencies

1 The same fact is noted by Michael, op. cit., p. 43. 
increased as the fit decreased in severity, and eventually all combined.

(b) During the cold stage the temperature rose throughout, the rise being greater than during any other period; but here also great variations existed, having their counterpart in variations in the severity of the fit.

Thus, in the cold stage, the temperature rises continuously when the fit is severe; then, as the severity lessens, there is a tendency for the rise at the termination of the cold stage to flag, and eventually to become stationary; then the range of each rise becomes less; and lastly, it oscillates. It also appears that the alteration first affects the commencement and termination of the cold stage, an oscillation in its middle indicating a greater diminution of the severity of the fit than at either end.

There was no connexion between the duration of the stage and the severity of the fit, as measured by the temperature. Thus, it lasted-

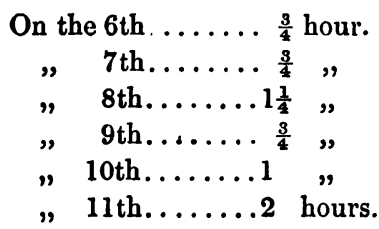

The fits were most severe on the 6 th and 7 th, and declined in severity till the 11th, when the fit was again more severe.

(c) During the hot stage the temperature continued to rise, and in its early part closely corresponded to the former periods.

From a careful examination of the charts, it appears that in the severer cases the temperature in the hot stage ran up at once to its acme, and had a tendency to remain permanent; the permanency not, however, being obtained at once nor retained throughout, the temperature oscillating both at the commencement and termination. In less severe cases it ran up slowly, and did not remain stationary, and when least severe, oscillated in its rise.

The temperature in those fits becoming less severe first lost its permanency, and next the temperature rose to a less extent 
and again became permanent; then, when they became still less severe, it rose to the same extent, but again lost its permanency. Again, in those cases where the temperature remained permanent, the hot stage ended at the termination of the permanent period in an oscillation, these cases being the severest at their own temperature. In all other cases the temperature fell before the sweating stage commenced, ending in an oscillation, and the less severe the fit the greater was the portion of the hot stage occupied by the fall of the temperature. Also the fit was less severe, and the fall greater, when the temperature in falling every now and then stood still for some time, and was still less severe when it oscillated.

(d) The temperature continued to fall through the sweating stage, and was often a long time before it reached the point from which it started. The temperature fell most rapidly in those cases in which the oscillations occurred, and least rapidly where the fall was continuous. Towards the termination of the sweating stage a rise occurred to a slight extent (perhaps followed by oscillations)-in four of the six fits. Thus, on April 6th, sweating commenced at $11 \cdot 15$, when the thermometer marked $1035^{\circ}$; at $2 \cdot 15$ the temperature had fallen to $100^{\circ}$; it then rose to $101^{\circ}$ at $2 \cdot 30$, to $101 \frac{2}{5}^{\circ}$ at 2.45 ; then fell to $100 \frac{3}{5}^{\circ}$ and $100^{\circ}$ at 3 and $3 \cdot 15$; then rose to $100 \frac{3}{5}^{\circ}$ at $3 \cdot 30$, and then finally fell regularly to $97 \frac{3}{5}^{\circ}$, a point not reached till seven o'clock. The charts show, at a glance, these slight but perfectly definite rises at this late period of the sweating stage.

\section{Urea.}

As the type of the disease in this man was quotidian, there was no opportunity of comparing the amount of urea on a fever and on a fever-free day. But the amount of urea passed in the fever-free hours was decidedly much smaller than might have been anticipated. He excreted only $0.650 \mathrm{grm}$. on an average per hour in the apyrectic period, which would give in twenty-four hours 15.600 grms., had the excretion remained at the same amount during 
the whole day. Now, a man of the same weight, between twenty and forty years of age, on a good diet, as this man was, would have secreted 32 grms. in the twenty-four hours, if he passed the average amount. Our patient was, however, older (fifty-nine), and would, no doubt, form less urea than a man at a more vigorous period of life. But it can hardly be supposed that the amount would be reduced so low as $15 \frac{1}{2}$ grms. in the twenty-four hours by this difference of age. It may, therefore, be concluded that, in accordance with Redenbacher's observations, the excretion of urea in the fever-free period was below the healthy amount.

The observations made by Traube, Redenbacher, and Hammond on the increase of urea during the cold and hot stages are entirely confirmed by this case, but a more minute statement of the kind and amount of the increase can now be given.

It must, however, be premised, that the only obvious causes of the increase of the urea in this case during the fit are, either the food taken at breakfast at 5 a.m., the fluid drunk during the fit, or the fit itself. No other known causes existed which could have had the effect of increasing the urea. The following objections to the idea of the food being the cause may be urged. That the amount of food was not great, and that the increase in the urea was far larger than has yet been noted after even the heaviest meal. For example, on the $7 \mathrm{th}$, the amount per hour rose from $0.684 \mathrm{grm}$. to $2 \cdot 176$, being an increase of more than 200 per cent.; on the 8th, from 0.654 to 3.474 , being an increase of nearly 500 per cent.; on the 9 th and 10 th, when the fits were slighter, the increase was less marked, though still considerable; while on the 11th, when the fit was severe, it was again 200 per cent. Such an amount is greater than has yet been found after an ordinary amount of food. ${ }^{1}$ The time, however, at which the urea increases after food accords with our case; for, augmenting even

1 Dr. Parkes has noted in one person without fever a rise from 0.665 grm. in a fasting hour to $1.554 \mathrm{grm}$. in a food hour, but this was after a hearty dinner. 
during the first hour after food, 1 it attains its maximum sometimes in the third hour $;^{2}$ sometimes, however, not till the seventh hour; usually, however, it reaches its maximum at the fourth hour.

Now, in this case food was taken between 5 and 6 a.m., and the maximum amount of urea secreted was during the cold stage, from 8 to 9.30 a.m., or in the fourth and fifth hours. But it will probably be conceded, after it has been shown how closely the amount of the urea was associated with the variation in the temperature, that its increase in the fourth and fifth hours after food was merely a coincidence, and was not owing to the very moderate breakfast, but to the fact of the highest temperature occurring at this time. On one day, moreover, he took no food, having no appetite, and on this day the usual increase occurred. Again, after the fits were stopped by the quinine, the food was given him as usual, and the urine being collected on the same day, in the same way, comparatively little rise took place in the urea. These two last points, I conceive, set the question quite at rest.

With respect to the amount of fluid drunk, this could have no effect on the urea, as very little fluid was taken till after the time when the urea had commenced to rise. The urea, moreover, reached its maximum often at the termination of the cold stage, whilst he seldom drank anything between his breakfast and the hot stage. $I$ believe, then, that I am justified in concluding that the rise in the amount of urea was not owing either to food or liquid. It must, therefore, have been owing to the fit.

'The urea begins to increase in amount before the cold stage, as judged of by the first feeling of shivering, in four of the five fits. Thus, it rose-

On the 7th, from 0.666 to 1.361 per hour.

" 8th, from 0.654 to 1.425 "

"9th, from 0.927 to 1.351 ",

" 11 th, from 0.614 to 1.924 ,

1 Voit, quoted by Meissner, "Report on Phys. for 1857," in Henle's

' Zeitschrift,' p. 352.

2 Becker, Henle's 'Zeitschrift,' 1855, p. 549. 
The time it commenced to rise before the subjective fit varied. Thus-

On the 7 th.... $\frac{3}{4}$ hour before.

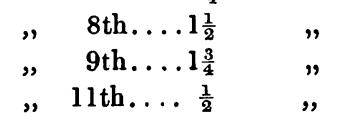

It often began to increase, indeed, even before the temperature began to rise. Thus, as the temperature on the 7 th rose before the fit $\frac{3}{4}$ of an hour, on the 8th $1 \frac{1}{4}$, on the 9 th $\frac{3}{4}$, the urea on those days commenced to rise previous to any similar change in the temperature.

Great apparent irregularity existed in the rise of urea, but a close correspondence is observed between these variations and similar ones in the temperature.

The alteration in the above case of urea and the temperature did not always exactly agree in time, though this was the rule, but sometimes the alteration in the temperature did not occur till after the alteration in the urea; the reverse never happened.

The quantity of urea continued to increase, and reached its highest point either at the termination of the cold stage, as on the 8th and 11th, or at the commencement of the hot, as on the 6th, 9th, 10th, and 12th. It then began to fall in quantity, slowly at first. On the 6th and 10th the temperature and urea commenced to fall simultaneously. On the 7th, 8th, 9th, and 11th, the temperature continued to rise, notwithstanding the fall in the urea. Up to the period when the urea commenced to decrease, the temperature rose rapidly, each rise being extensive, but after that, at the point where the urea commenced to fall, the temperature either oscillated, or every rise remained stationary for a short time, the rise being always slow and by small additions.

The urea continued to fall slowly from the end of the cold, or from the commencement of the hot stage, till the sweating stage began; and the temperature corresponding in time to the latter part of this slow decrease, after reaching its height, fell also slowly and slightly. 
From the following table it appears that no close correspondence existed between the fall in the temperature towards the close of the hot stage and the decrease in the amount of ureà.

\begin{tabular}{|c|c|c|c|c|c|c|}
\hline Date. & Fall in Urea. & $\begin{array}{c}\text { Fall in Tempe- } \\
\text { rature in same } \\
\text { time. }\end{array}$ & $\begin{array}{c}\text { Temperature } \\
\text { oscillated. }\end{array}$ & $\begin{array}{c}\text { Tendency to } \\
\text { be stationary. }\end{array}$ & $\begin{array}{c}\text { Temperature } \\
\text { fell continu- } \\
\text { ously. }\end{array}$ & $\begin{array}{c}\text { Fall of Urea } \\
\text { reduced to } \\
\text { quantity for } \\
\text { 10 Fahr. }\end{array}$ \\
\hline 6 th & 0.268 & $\frac{1}{5}^{\circ}$ & & - & & 1.346 \\
7 th & 0.830 & $1^{3^{\circ}}$ & & & - & 0.533 \\
8 th & 1.452 & $3^{\circ}$ & & & - & $\ldots$ \\
9 th & 0.884 & $1^{\circ}$ & & & - & 0.884 \\
10 th & 0.261 & $3^{\circ}$ & & - & & 0.435 \\
11 th & 1.000 & $2_{\frac{4}{5}}^{\circ}$ & - & & & 0.357 \\
\hline
\end{tabular}

In the first column the date is given; in the second the fall in the amount of urea, corresponding in time to the fall in the temperature, from its highest point to the commencement of the sweating stage, is given; next, the number of degrees the temperature fell in the same time; then, in three columns, the character of the fall is given; and in the last column the fall in the amount of urea is reduced to the quantity corresponding to each degree. But though there is no intimate connexion, still the greater the fall in the temperature the greater is the decrease in the quantity of urea. At the same time the character of the fall varied; thus, sometimes the temperature showed a tendency to remain stationary, then the urea fell but little, as on the 6th and 10th. On other days the temperature fell gradually, and then the fall in urea rather increased. The greatest fall occurred on those days when the temperature oscillated greatly. Thus, the least decrease in urea corresponded to that temperature which has a tendency to remain stationary, more when it fell slowly but continuously, and much the most when it oscillated, as on the 11th; and it is 
possible to judge of the rapidity of the decrease of the urea by the character of the temperature.

The temperature has been shown to fall either at the close of the hot or the commencement of the sweating stage. A similar fall occurred in the urea, and the amount of the decrease of urea corresponded to the length of the oscillation, and the subsequent rise in the urea corresponded to the rise in the oscillation, though the whole oscillation always occurred in an hour previous to that in which the subsequent rise in the urea occurred.

\begin{tabular}{|c|c|c|c|c|}
\hline Date. & $\begin{array}{c}\text { Fall in } \\
\text { Temperature. }\end{array}$ & Fall in Urea. & $\begin{array}{c}\text { Rise in } \\
\text { Temperature. }\end{array}$ & Rise in Urea. \\
\hline 6th & $1 \frac{3{ }^{\circ}}{5}$ & $\left\{\begin{array}{c}1.820 \\
\text { to } \\
1.289\end{array}\right\}$ & $1 \frac{3}{5}^{\circ}$ & $\left\{\begin{array}{c}1.289 \\
\text { to } \\
1.620\end{array}\right.$ \\
\hline 7th & $1^{\circ}$ & $\begin{array}{c}1.287 \\
\text { to } \\
0.838\end{array}$ & $1^{\circ}$ & $\begin{array}{c}0.838 \\
\text { to } \\
1.222\end{array}$ \\
\hline 8th & $1 \xi^{\circ}$ & $\begin{array}{c}3.474 \\
\text { to } \\
0.644\end{array}$ & $f^{\circ}$ & $\begin{array}{c}0.644 \\
\text { to } \\
1.378\end{array}$ \\
\hline 11th & $1 \frac{3{ }^{\circ}}{5}$ & $\left\{\begin{array}{c}1.839 \\
\text { to } \\
1.045\end{array}\right\}$ & $\frac{10}{3}$ & $\left\{\begin{array}{c}1.045 \\
\text { to } \\
1.356\end{array}\right.$ \\
\hline
\end{tabular}

A slight rise, however, took place at the same period, even when the temperature remained permanent, but then the increase was small in amount.

On the 9th, the temperature fell, but did not oscillate; the fall in the urea was not so great as when the temperature oscillated.

A relationship in the latter part of the sweating stage between the variation in the urea and temperature existed, corresponding to what is stated above. Thus, on the 6th, after the usual oscillation, the temperature had a tendency to fall, and then to remain stationary for some time, and again to fall and remain a second time stationary. During this time the urea fell in quantity slowly. The temperature then took a great fall, and.oscillated greatly, and at the same time the fall in urea was very great. 
On the 7 th the temperature fell slowly, and often remained stationary; at the same time the urea fell slowly, and, like the temperature, did not reach the normal amount till late in the afternoon.

The same close correspondence exists between the other cases.

In order to test still further the relationship between the urea and the temperature, the following method was adopted. The total amounts of urea excreted during the fit, the quantity excreted during the rise and fall of temperature, during the period immediately before the fit, and during the cold and hot stages, respectively, have been added up and divided by the number of degrees the temperature rose or fell in the corresponding periods. By this means the amounts of the urea secreted during the whole and each of the divisions of the fit were reduced to a common standard, and could thus be compared more easily with one another.

Table ${ }^{1}$ to show the amount of Urea corresponding to each degree of Fahrenheit of abnormal heat.

\begin{tabular}{|c|c|c|c|c|c|c|}
\hline 㟧 & 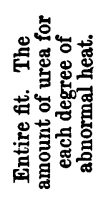 & 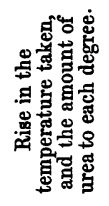 & 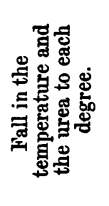 & 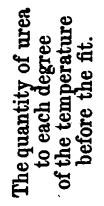 & 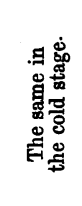 & 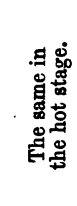 \\
\hline 6th & 1.557 & 0.626 & 0.930 & ... & 0.339 & 3.560 \\
\hline $7 \mathrm{th}$ & 1.413 & 0.615 & 0.798 & 0.972 & 0.391 & 1.609 \\
\hline $8 \mathrm{th}$ & 1.508 & 0.903 & 0.722 & $2 \cdot 163$ & 0.735 & $1 \cdot 444$ \\
\hline 9 th & $1 \cdot 460$ & 0.675 & 0.710 & 0.566 & 0.246 & 2.793 \\
\hline $0 \operatorname{th}$ & $1 \cdot 298$ & 0.718 & 0.746 & 0.657 & 0.617 & $1 \cdot 381$ \\
\hline 11 th & $1 \cdot 781$ & 0.712 & $1 \cdot 280$ & 0.601 & 0.590 & 0.868 \\
\hline
\end{tabular}

1 In this table each of the quantities of urea correspond to $1^{\circ}$ of temperature. In the first column the date is given; in the second, the whole amount of urea passed during the entire fit (the fit being considered to 
On comparing the different days, the closest correspondence existed when the whole fit was taken. The extreme in column two being taken, the difference only amounted to one fifth of a degree. The rise and fall also closely corresponded. The extreme again being taken, a difference amounting to one third of a degree was found.

As the duration of the fit might have varied greatly, and so the above mode of comparison of the different days one with the other have been invalidated, the following tables have been worked out.

The first shows the duration of the fit on each day.

\begin{tabular}{|c|c|}
\hline \multicolumn{2}{|c|}{6 th.....7 $\frac{1}{4}$ hours' duration } \\
\hline 7 th $\ldots \ldots 8$ & " \\
\hline 8 th....8 $8 \frac{1}{4}$ & " \\
\hline 9 th.....7 $\frac{3}{4}$ & " \\
\hline 10th.....8 & " \\
\hline 11 th......7 $\frac{1}{2}$ & , \\
\hline
\end{tabular}

commence with the rise of the temperature and the increase of the urea and chloride of sodium). In the third column the rise (in the temperature) only is taken, and when the temperature remained stationary at its highest point for some time the time of the rise is calculated up to the middle of the stationary part. In the next column the fall, calculated in the same way, is given. Then the cold and hot stages are given separately.

The amount of urea varied in this patient; for the night urine varied on one day greatly from the quantity passed during a similar period on other nights. This day, the 9 th (the urine of the night before not having been saved), the amount of urea corresponding to each degree was greatly in excess ; but on assuming that the quantity passed during the first hour $0.900 \mathrm{grm}$.) was the quantity normal to him for that day, and so deducting the excess, a close correspondence to the other days resulted. Thus, when the whole amount of urea was calculated as it stood, to each degree 2.043 grms. were found to correspond; but when the additional 300 grms. were deducted, then the quantity per degree was 1.460 ; and throughout all the different comparisons it will be then found closely to agree. On the 10th, again, the normal excretion was below par (0.170 grm. per hour), which also prevented any comparisons from being made. When this was raised to $0.600 \mathrm{grm}$, then a much closer correspondence to the other days was found. 
Another calculation must now be made. On three days the urine was collected through the previous night; taking that hourly amount, and assuming that to be the amount normal to the man through that day, if there had been no disturbing influences, and deducting that quantity from the quantity passed hourly through the fit, the increase only is obtained, and this divided by the number of degrees the temperature rose, the comparison is then found to be very close.

April 7th. ....0638 urea to each degree of abnormal heat.

" 8th....0.618 " " " " "

If this table be compared with the former one, the comparison will be found to be even much closer. Unfortunately, the amount during the night was not determined except on these three days, so that this mode of calculation is not applicable to all the fits.

On looking at the second column of the table given at page 377, where the total amounts are compared, it is found that on the 6th, 8th, and 11 th, the quantity in excess is somewhat over other days. The temperature on the 6th and 8th remained permanent after reaching its highest point. Thus, on the 6th it remained at $105^{\circ}$ for two hours and a half; on the 8th at $103 \frac{4}{5}^{\circ}$ for one hour and a quarter; but when the amount passed during these permanent periods is deducted, then the urea on the 6 th fell to $1 \cdot 277$ grm., and on the 8th to 1.366 grm., bringing each on a level with the 10th. On the 11th, the increase in urea occurred entirely in the fourth column, that is, during the fall of the temperature, the amount passed during the rise corresponding closely to the other days; and on examining the sweating stage on the 1lth, there is found a great and sudden increase at its very termination, and this excessive quantity being replaced by the quantity passed on other days at the same period, the amount corresponding to each degree was ] 510 , closely coinciding with the other days. 
That the increase on the 6th and 8th was due to the above is rendered probable by the following statement: The whole quantity of urea passed on the 6th, during the stationary period of two hours and a half, was $1.957 \mathrm{grm}$. On the 8th, for one hour and a quarter, the quantity was 1.155. When compared to equal time, that is, the two hours and a half reduced to one hour and a quarter, then, on the 6th, the amount of urea was 0.978 , corresponding closely to the quantity passed in the same time on the 8th. From this it would appear that the same amount of urea corresponds to $1^{\circ}$, when the temperature is permanent, whether it be at a high temperature or not, whilst the second table shows that every degree in the hot stage corresponds to a much greater amount of urea than in the cold or any other stage, whilst the temperature is rising; thus showing, that the higher the temperature, the more urea corresponds with each rise of a degree than formerly, and thus accounting in some measure for the greater quantity of urea to each degree, when the whole fit is compared, in the more severe fits.

The very close correspondence between the temperature and the urea seems to be thus placed beyond doubt; in fact, the one may be calculated from the other. An example or two will illustrate this.

Thus, on-

April 6th, the amount of urea excreted during the fit was 11.097 grammes; taking 1.503 gramme as the average quantity (all the degrees being taken) corresponding to each degree, this gives a rise of $7^{\circ}$, or a little over; the actual rise was from $98 \frac{1}{5}$ to 105 , or $6 \frac{4}{5}^{\circ}$.

April 7 th, the total amount of urea during the fit was 10.635 grammes. The rise in the temperature here should be $7^{\circ}$; the actual rise was $6 \frac{4}{5}^{\circ}$.

April 8th, the total amount of urea excreted was $9 \cdot 353$ grammes, which would imply a rise in the temperature of $6^{\circ}$; the actual rise was from $97 \frac{4}{5}$ to $103 \frac{4}{5}$, being exactly $6^{\circ}$. 


\section{Chloride of Sodium.}

The chloride of sodium, to a very great extent, agreed with the urea in its relationship to the temperature. Traube's statement on this point is therefore confirmed. For the most part, the remarks above made on the urea hold good for the chloride of sodium; still some differences occurred.

On the 8th, the urea between $7 \cdot 30$ and 8 a.m. remained stationary, whilst the chloride of sodium rose continuously.

9th.-Between 8 and 9 a.m. the urea fell, the temperature corresponding, but the chloride of sodium rose to double its quantity.

Again, during the decline of the fit, they differed on the 8th and 9th; the urea at its termination rose somewhat, whilst the chloride of sodium continued to fall.

The following table corresponds to one given for the urea, and shows the intimate connexion between the severity of the fit and the amount of chloride.

\begin{tabular}{|c|c|c|c|c|c|c|}
\hline هึँ & 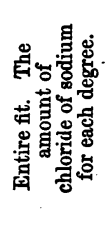 & 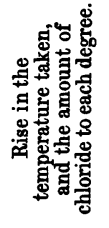 & 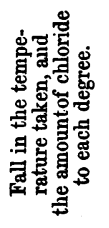 & 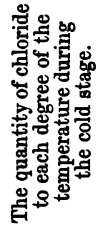 & 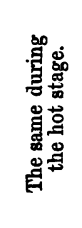 & 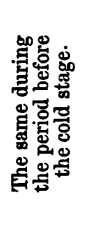 \\
\hline 6th & 0.195 & 0.085 & 0.086 & 0.027 & 0.293 & $\ldots$ \\
\hline 7th & 0.225 & $0 \cdot 159$ & 0.066 & 0.085 & 0.259 & 0.640 \\
\hline 8th & $0 \cdot 171$ & 0.107 & 0.078 & 0.131 & $0 \cdot 162$ & 0.134 \\
\hline $\begin{array}{l}9 \text { th } \\
10 \text { th }\end{array}$ & 0.241 & 0.150 & $\begin{array}{l}0.062 \\
\text { Lost. }\end{array}$ & 0.175 & 0.702 & $0 \cdot 103$ \\
\hline IIth & $0 \cdot 180$ & $0 \cdot 149$ & 0.041 & $0 \cdot 102$ & 0.176 & 0.785 \\
\hline
\end{tabular}

Here, as occurred in the urea, the patient on two days 
passed a different quantity normally from what he had on former days; so that on one day, the 8th, it was necessary to add $0.022 \mathrm{grm}$. to each hour to bring it up to the other days. On the 11 th it was necessary to subtract $0.044 \mathrm{grm}$.

On the 6th the urine was not collected before the commencement of the cold stage, so that the amount for each degree is less than it would otherwise have been in the third and fourth columns.

When the extremes in the third column were compared, a difference corresponding to one third of a degree of temperature occurred. When the fourth column was compared, excluding the 6th, a difference of one third of a degree occurred. In the fifth column, a difference corresponding to less than one third occurred, excluding the 11th, on which day the chloride fell to its normal amount before the fit had ended.

In the cold stage an enormous difference was found.

In the hot the difference corresponded to half of a degree.

Beyond these above differences, all that has been said regarding the urea applies equally to the chloride of sodium.

\section{Water of the Urine.}

In rising and falling in quantity, the water has a very close correspondence to the urea, though there is very little proportion between the different rises and falls in the two. On the 6th, 8th, and 9th, they corresponded in rising and falling at the same periods. On 11th and 7th the quantity of urine in the hot stage falls so considerably, that in the commencement of the sweating stage a slight rise occurs, this being followed, however, by a decided fall during the second hour.

The quantity of urine thus corresponding to the urea, must, like it, correspond somewhat to the variations in the temperature. That the quantity stands in close relation to the intensity of the fit is seen from the following table. 


\begin{tabular}{|c|c|c|c|}
\hline Date.1 & $\begin{array}{c}\text { Quantity } \\
\text { of urine in } \\
\text { the fit. }\end{array}$ & $\begin{array}{c}\text { Number of } \\
\text { degrees tempe- } \\
\text { rature rose. }\end{array}$ & $\begin{array}{c}\text { Quantity } \\
\text { of urine to } \\
\text { each degree. }\end{array}$ \\
\hline 6th & 608 c.c. & $5 \frac{1}{5}$ & 117 c.c. \\
7th & 411 c.c. & $5 \frac{4}{5}$ & 71 c.c. \\
8th & 449 c.c. & $6 \frac{1}{5}$ & 72 c.c. \\
9th & 382 c.c. & $5 \frac{2}{5}$ & 71 c.c. \\
11th & 435 c.c. & $5 \frac{4}{6}$ & 75 c.c. \\
\hline
\end{tabular}

It has been shown that some correspondence exists between the oscillation of temperature at the commencement of the sweating stage and the fall and subsequent rise in the amount of urea. The following table shows the relationship between the same oscillation and the fall in the amount of urine passed.

On the 6th and 11th it has been said that the amount of urine secreted was so small during the hot stage that it rose somewhat at the commencement of the sweating, so that no comparison can be given on those days between the fall of the oscillation and the quantity of urine. In the next table, in the first column, as usual, the day of the month is given; in the second, the fall of the temperature in the oscillation; in the third, the fall in the amount of urine; in the fourth, the amount reduced to a degree; in the fifth column, the rise of the temperature in the oscillation is given; in the sixth, the rise in the amount of urine in the hour subsequent; and in the seventh, the quantity is reduced to that corresponding to a degree:

1 In the first column the date is given. In the second, the total quantity of urine passed during the fit. In the third, the number of degrees the temperature rose during the fit. In the fourth, the number of cubic centimetres corresponding to each degree. Excluding the first day, a very close correspondence existed. 


\begin{tabular}{|r|l|l|c|c|c|c|}
\hline 6th & \multicolumn{2}{|c|}{ Urine rose } & $\ldots$ & $1 \frac{3}{6}^{\circ}$ & 0.030 & 0.020 \\
7th & $1^{\circ}$ & 0.030 & 0.030 & $1^{\circ}$ & 0.017 & 0.017 \\
8th & $1^{\circ} \frac{3}{6}^{\circ}$ & 0.039 & 0.025 & $\frac{4}{6}^{\circ}$ & 0.025 & 0.030 \\
11 th & \multicolumn{2}{|c|}{ Urine rose } & $\ldots$ & $\frac{1}{6}^{\circ}$ & 0.007 & 0.035 \\
\hline
\end{tabular}

From this limited table, no great correspondence can be traced.

But though the urea, chloride of sodium, and water, thus constantly show a close correspondence to the temperature, the relative amount of rise was different in these three ingredients.

This indeed was shown well during the analysis, in which 10 c.e. of urine were taken; the amount of mercury solution required for the amount of urea varied greatly from hour to hour, showing no regularity of rise; whilst, on the other hand, the amount required in testing for the chloride gradually rose and then gradually sank, often again rising somewhat at the very close of the fit. Thus, to take the 7th of April :

UREA.

\begin{tabular}{|c|c|c|c|}
\hline Hour. & $\begin{array}{c}\text { Amount of } \\
\text { mercury solution } \\
\text { required for } \\
100 \text { pints of urine. }\end{array}$ & Same for NaCl. & $\begin{array}{r}\text { Hourly amount } \\
\text { of water passed. }\end{array}$ \\
\hline 7 a.m. & 298 c.c. & 48 c.c. & 25 c.c. \\
8 a.m. & 198 c.c. & 144 c.c. & 80 c.c. \\
8.30 a.m. & 188 c.c. & 135 c.c. & 136 c.c. \\
10.30 a.m. & 224 c.c. & 90 c.c. & 62 c.c. \\
12 noon. & 272 c.c. & 45 c.c. & 33 c.c. \\
1 p.m. & 268 c.c. & 45 c.c. & 50 c.c. \\
3 p.m. & 248 c.c. & 36 c.c. & 50 c.c. \\
5 p.m. & 258 c.c. & 18 c.c. & 28 c.c. \\
\hline
\end{tabular}

The urea varies in its proportion to the water; thus, during excessive diuresis, the per-centage amount falls, whilst, on the other hand, the per-centage amount of chloride even then increases, up to the time the greatest amount is poured out, then it as steadily falls, even when the water fluctuates 
greatly. These remarks apply to the per-centage of chloride of sodium in the urine.

It appears that the amount of urea undergoes an increase definite in amount, independent of the water. The chloride of sodium also undergoes a definite increase, which, also, is independent of the amount of water; but the water being increased, the same per-centage of chloride is poured out as would have been the case if a smaller amount of water had been voided, the per-centage not being lowered by an excess of water, as is the case with urea.

The chloride has thus a tendency to rise and fall steadily, not observing the various alterations corresponding to temperature that the urea does, but the water, corresponding to the urea in this respect, causes variations of the same character in the total amount of chloride poured out.

The time of greatest per-centage excretion of chloride of sodium does not always correspond to the greatest hourly excretion.

Thus, on April 6th, the greatest amount of saturation was at 8 a.m., whilst the greatest hourly excretion was at 8.30, when the water was at its greatest amount.

7th.-The hourly excretion and the per-centage amount agreed in the time at which they occurred, and so also did the water.

8th.-The same occurred on this day.

9th and 10th.-The same occurred also on these days.

11th.-The per-centage amount of chloride was greatest at 9 a.m., whilst the hourly amount excreted was greatest at 10, the water being most abundant during the last period.

The urea, on the other hand, often decreased in percentage during the fit, especially if the increase in the water was great, its highest per-centage amount corresponding to the lesser amount of water. Thus, on April 6th, the per-centage amount decreased through the entire fit. The decrease was, however, much more gradual at its commencement.

7th.-The greatest per-centage amount was at 7 a.m., the amount of water being 25 c.c. for the hour. The water

XLII. 
then rose to 80 c.c., and the per-centage amount of urea fell; the amount of mercury solution required for 10 c.c. of urine fell from 29 c.c. to 19 c.c. The water then again rose to 136 c.c., and the solution of mercury required fell in amount to 18 c.c. The water next fell to 62 c.c., and the solution of mercury rose to $22 \cdot 6$ c.c. The water again fell to 33 c.c., and the amount of the solution required rose to $27 \cdot 4$ c.c. The water next rose to 50 c.c., and the solution required fell to 26.4 c.c. The water then remained at 50 c.c., but the solution fell to 24 c.c. Then the water fell to 28 c.c., and the quantity of the solution rose to 25 c.c. $^{1}$

From these facts it is evident that both the urea and chloride increase, independent of the influence of the amount of water; that any increase in the latter does not modify the aggregate amount of urea, but that it does that of the chloride.

No connexion exists between the quantity of urine passed during the entire fit and the amount of water drunk.

This is seen in the following table $:^{2}$

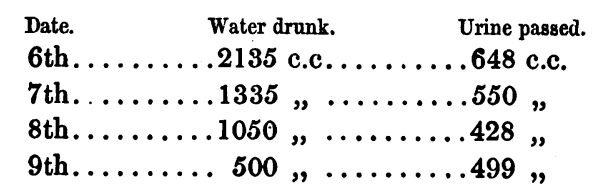

The urine was passed much more equally as regards the different periods than the water drunk, for the entire quantity was mostly drunk during the hot stage only.

Thus, the urine, urea, and chloride of sodium, were independent, to a large extent, of the quantity drunk,

1 Every c.c. of the mercury solution corresponds to 10 milligrammes of urea.

2 As usual, the date is given in the first column; in the second, the quantity of water drunk during the entire fit, and in the third, the amount of urine passed during the entire fit, are given. 
APRIL 12TH

Phenomena of a Fit modified by Quinine.

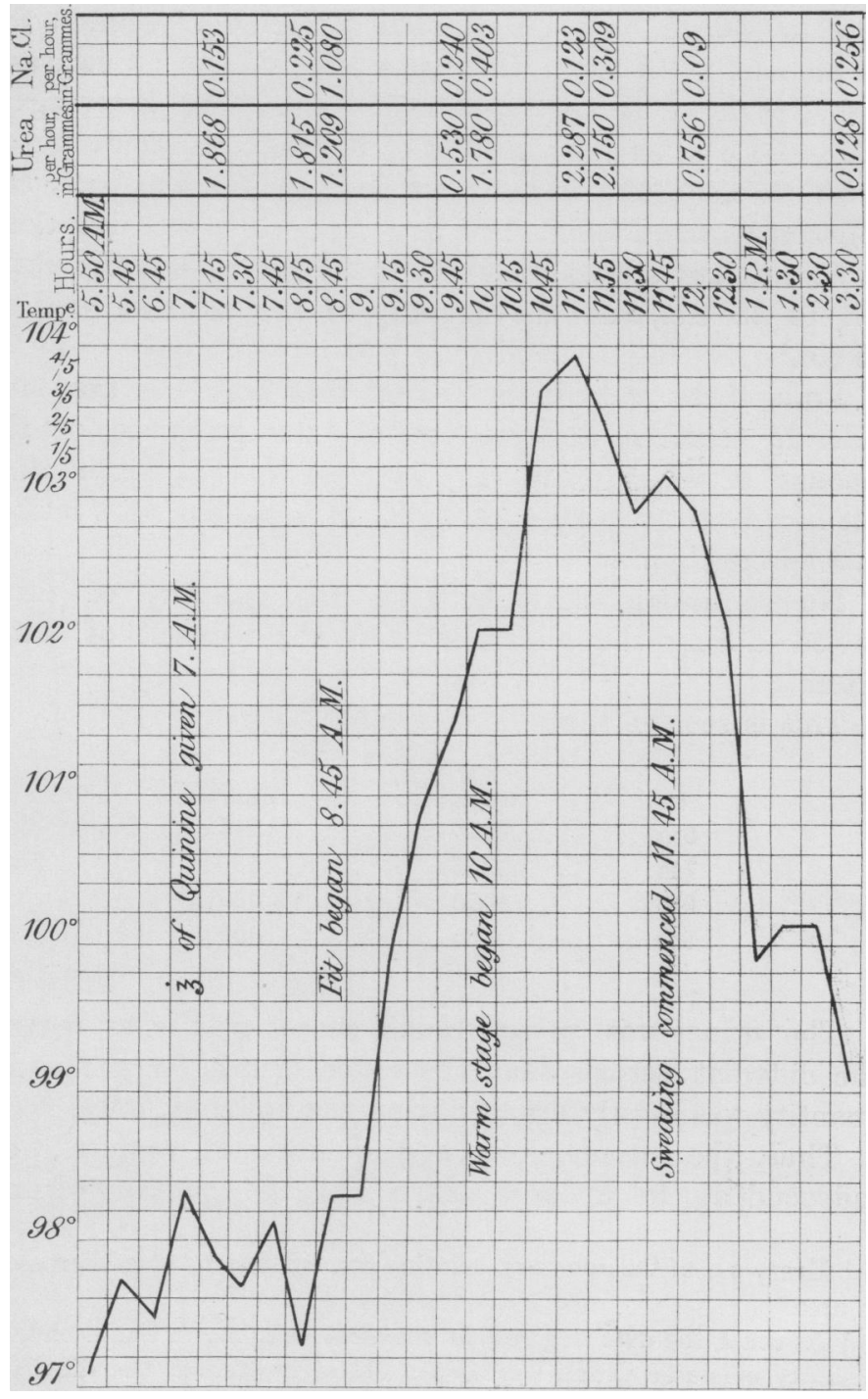

wwest lith. 
though some connexion appeared to exist, as, when the patient drank copiously, the next time the urine was collected it was found to be somewhat in excess; but this might be a mere coincidence.

TABLe.

APRIL 12.-UREA.

\begin{tabular}{|c|c|c|c|c|}
\hline Stage. & Hour. & $\begin{array}{l}\text { Total Quantity } \\
\text { in this time. }\end{array}$ & $\begin{array}{l}\text { Quantity per } \\
\text { hour. }\end{array}$ & $\begin{array}{l}\text { Average Quantity } \\
\text { per hour during } \\
\text { period. }\end{array}$ \\
\hline $\begin{array}{l}\text { Before fit } \ldots \ldots \\
\text { Cold } \ldots \ldots \ldots \ldots \\
\text { Hot } \ldots \ldots \ldots \ldots \\
\text { Sweating } \ldots \ldots\end{array}$ & $\begin{array}{l}6 \cdot 15 \text { to } 7 \cdot 15 \\
7 \cdot 15 \text { to } 8 \cdot 15 \\
8 \cdot 15 \text { to } 8 \cdot 45 \\
8 \cdot 45 \text { to } 9 \cdot 45 \\
9 \cdot 45 \text { to } 10 \\
10 \text { to } 11 \\
11 \text { to } 11 \cdot 30 \\
11 \cdot 30 \text { to } 12 \cdot 30 \\
12 \cdot 30 \text { to } 3 \cdot 30\end{array}$ & $\begin{array}{c}\text { Grammes. } \\
1.868 \\
1 \cdot 815 \\
0.604 \\
0.530 \\
0.445 \\
2 \cdot 287 \\
1 \cdot 075 \\
0.756 \\
0.384\end{array}$ & $\begin{array}{c}\text { Grammes. } \\
1.868 \\
1.815 \\
1 \cdot 209 \\
0.530 \\
1.780 \\
2 \cdot 287 \\
2 \cdot 150 \\
0.756 \\
0.128\end{array}$ & $\left\{\begin{array}{l}\text { Grammes. } \\
1 \cdot 630 \\
2 \cdot 310 \\
2.219 \\
0.442\end{array}\right.$ \\
\hline \multicolumn{5}{|c|}{ CHLORIDE OF'SODIUM. } \\
\hline $\begin{array}{l}\text { Before fit } \ldots \ldots . \\
\text { Cold } \ldots \ldots \ldots \ldots \\
\text { Hot } \ldots \ldots \ldots \ldots . .\end{array}$ & $\begin{array}{l}6 \cdot 15 \text { to } 7 \cdot 15 \\
7 \cdot 15 \text { to } 8 \cdot 15 \\
8 \cdot 15 \text { to } 8 \cdot 45 \\
8 \cdot 45 \text { to } 9 \cdot 45 \\
9 \cdot 45 \text { to } 10 \\
10 \text { to } 11 \\
11 \text { to } 11 \cdot 30 \\
11 \cdot 30 \text { to } 12 \cdot 30 \\
12 \cdot 30 \text { to } 3 \cdot 30\end{array}$ & $\begin{array}{l}0 \cdot 153 \\
0 \cdot 225 \\
0 \cdot 540 \\
0 \cdot 240 \\
0 \cdot 100 \\
0.625 \\
0 \cdot 154 \\
0 \cdot 090 \\
0.708\end{array}$ & $\begin{array}{l}0 \cdot 153 \\
0.225 \\
1 \cdot 080 \\
0 \cdot 240 \\
0 \cdot 403 \\
0.625 \\
0.309 \\
0.090 \\
0.256\end{array}$ & $\left\{\begin{array}{l}0.153 \\
0.225 \\
1.080 \\
0.321 \\
0.467 \\
0.173\end{array}\right.$ \\
\hline \multicolumn{5}{|c|}{ QUANTITY OF URINE PASSED. } \\
\hline $\begin{array}{l}\text { Before fit } \ldots \ldots . \\
\text { Cold } \ldots \ldots \ldots \ldots \\
\text { Hot } \ldots \ldots \ldots \ldots \ldots\end{array}$ & $\begin{array}{l}6 \text { to } 7 \cdot 15 \\
7 \cdot 15 \text { to } 8 \cdot 15 \\
8 \cdot 15 \text { to } 8 \cdot 45 \\
8 \cdot 45 \text { to } 9 \cdot 45 \\
9 \cdot 45 \text { to } 10 \\
10 \text { to } 11 \\
11 \text { to } 11 \cdot 30 \\
11 \cdot 30 \text { to } 12 \cdot 30 \\
12 \cdot 30 \text { to } 3 \cdot 30\end{array}$ & $\begin{array}{r}73 \text { c.c. } \\
75 \text { c.c. } \\
54 \text { c.c. } \\
25 \text { c.c. } \\
84 \text { c.c. } \\
125 \text { c.c. } \\
86 \text { c.c. } \\
32 \text { c.c. } \\
128 \text { c.c. }\end{array}$ & & \\
\hline
\end{tabular}

On the 12th, everything being conducted in the same manner, upon the temperature commencing to rise, the patient was given $\vartheta_{j}$ of quinine, which caused the tempera- 
ture to fall again. It continued to fall for half an hour, and then began to rise; the cold stage came on an hour later than on the previous day. The fit, however, was afterwards as severe as usual. The effects on the urea corresponding to this fall cannot be ascertained, as, for some reason, the amount secreted was three times as great as on previous days, for the first two hours it was collected; it then fell somewhat, but continued high throughout the fit, the quantity to each degree being 0.980 grammes.

The temperature obeyed all the rules laid down previously-rising to the commencement of the cold stage; then remaining permanent for half an hour; then rising through the whole of the cold stage, the latter being shorter than the former; and just at the commencement of the hot stage, it again remained stationary for a quarter of an hour; then rose, but began to fall before the sweating stage commenced, and at that point oscillated, the oscillation being small; it then fell rapidly.

The urea corresponded also to these variations, after the manner described. Thus, it fell where the temperature remained stationary, but the fall was out of proportion to the alteration in the temperature, being very great. Possibly, this was due to the quinine. It then rose rapidly, reaching its highest point at the same time as the temperature. It fell slowly during the latter part of the hot stage, then fell greatly during the oscillation at the commencement of the sweating stage; but as the urea did not subsequently rise, the rise in the oscillation of the temperature was only one fifth; then the urea fell greatly.

The chloride of sodium differed somewhat from the urea at the commencement and termination. Thus, though an unusual quantity was passed in the first two hours, like the urea, still it did not fall when the temperature began to rise a second time, but continued rising throughout; just before the cold stage it reached its highest point, arriving at the very unusual quantity of $1.080 \mathrm{grm}$. 
After this it corresponded in its variations to the urea, except in the second hour of the sweating stage, when, instead of continuing to fall, it rose considerably. The rise in the hour subsequent to the oscillation in the temperature was very extensive.

Considering the fit to have commenced on this day, at $7 \cdot 15$ a.m., the amount for each degree was 0.396 , a larger quantity (as is also the case with the urea) than occurred on other days; but as the amount passed for some hours before the fit was unusually large, it is probable that the quantity normal for that day was in excess.

The water in its variations corresponded to the urea, except at its very termination (that is to say, the second hour of the sweating stage), when it rose considerably.

The amount for each degree was 105 c.c. It is rendered most highly probable that the reason for the amount for each degree being greater than usual in urea, salt, and water, is, that the normal quantity was in excess on this day, for it is found that the increase in each is proportionate.

The quantity he drank was not taken down on this day. Thus the only influence that can be ascribed to the quinine is the lowering of the temperature and the postponement of the fit.

Examination of the Urine on April 13th, Oij of Quinine having been taken the day before, the fit being entirely absent.

On the 13th no fit occurred. The patient took, without leave, another scruple of quinine the evening before. The temperature remained at $97^{\circ}$ the entire day, with very slight variations, never amounting to more than $\frac{2^{\circ}}{5}$. But, notwithstanding this equality of temperature, the urea and chloride of sodium underwent an increase. The urine was collected through the night. 
UREA.

\begin{tabular}{|c|c|c|c|}
\hline Hour. & $\begin{array}{l}\text { Quantity per } \\
\text { hour. }\end{array}$ & Hour. & $\begin{array}{c}\text { Quantity per } \\
\text { hoư. }\end{array}$ \\
\hline $\begin{array}{l}3.30 \text { p.m. to } 6.30 \text { a.m. } \\
6.30 \text { to } 7 \cdot 30 \text { a.m. } \\
7.30 \text { to } 8.30 \text { a.m. } \\
8.30 \text { to } 9.30 \text { a.m. } \\
9 \cdot 30 \text { to } 10.30 \text { a.m. } \\
10.30 \text { to } 11.30 \text { a.m. } \\
11.30 \text { to } 12.30 \text { p.m. } \\
12.30 \text { to } 1.30 \text { p.m. }\end{array}$ & $\begin{array}{l}\text { Grammes. } \\
0 \cdot 610 \\
1 \cdot 340 \\
1 \cdot 122 \\
1 \cdot 150 \\
1 \cdot 412 \\
0 \cdot 803 \\
0-999 \\
0 \cdot 606\end{array}$ & $\begin{array}{l}3.30 \text { p.m. to } 6.30 \text { a.m. } \\
6.30 \text { to } 7.30 \text { a.m. } \\
7.30 \text { to } 8.30 \text { a.m. } \\
8.30 \text { to } 9.30 \text { a.m. } \\
9.30 \text { to } 10.30 \text { a.m. } \\
10.30 \text { to } 11.30 \text { a.m. } \\
11.30 \text { to } 12.30 \text { p.m. } \\
12.30 \text { to } 1.50 \text { p.m. }\end{array}$ & $\begin{array}{l}\text { Grammes. } \\
0.057 \\
0.060 \\
0.082 \\
0.096 \\
0.138 \\
0.086 \\
0.091 \\
0.027\end{array}$ \\
\hline
\end{tabular}

Thus, though the patient experienced no change as regards his sensations, and his temperature remained the same throughout the day, a similar change to that occurring on the previous days was observed in the urea and chloride of sodium. The fit, as judged by the urine, commenced at 6.30 a.m. The urea then fell somewhat during the next hour, rising again steadily up to 10.30 a.m., when it had reached its highest point. It then fell greatly, and this was followed by a slight rise, and then again fell to the amount normal to this man. The fall, immediately after the first rise, probably corresponded to the termination of the period prior to the cold or the commencement of the cold stage ; and had the temperature risen, it would probably at this point have either oscillated or remained permanent for some time.

The next great fall, at 11.30 a.m., corresponded to the sweating stage, and would have been marked in the temperature by a great fall, and then, probably, the temperature would have remained stationary for half an hour, and not have risen, as the subsequent rise in the urea is small in amount. The urea after this small rise again falls to the normal amount.

The chloride also strictly followed the principles laid down, for, as has been shown, it has a tendency to rise continuously, an equal amount of urine being taken each hour, though, if the urine be much altered in 
quantity, this salt also falls and rises. Thus, the chloride rises continuously, and is marked by no fall after the first hour, but, corresponding to the great fall of urea at $11 \cdot 30$, it also falls and again rises slightly in the next hour, and then again falls to the amount normal.

The urea and chloride increase pari passu, and each reaches its height at the same hour.

The amount of urine, again, corresponded to the urea and chloride of sodium; it fell slightly after the first hour, then rose, reaching its highest point at the same time as the urea ; it then fell, but again rose somewhat, and then permanently fell.

\begin{tabular}{|c|c|c|c|c|}
\hline \multicolumn{2}{|l|}{3.30} & 6.30 & a.m.. & \\
\hline $6 \cdot 30$ & & $7 \cdot 30$ & $n$ & .......50 \\
\hline $7 \cdot 30$ & , & $8 \cdot 30$ & $n$ & $\ldots \ldots \ldots .46$ \\
\hline $8 \cdot 30$ & " & $9 \cdot 30$ & " & $\ldots \ldots \ldots 46$ \\
\hline $9 \cdot 30$ & , & $10 \cdot 30$ & $"$ & $\ldots \ldots \ldots 66$ \\
\hline$\cdot 3$ & $"$ & $11 \cdot 30$ & , & $\ldots \ldots 41$ \\
\hline $1 \cdot 3$ & 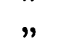 & $12 \cdot 30$ & p.m. & $\ldots 51$ \\
\hline & n. to & $1 \cdot 30$ & $"$ & $\ldots \ldots$ \\
\hline
\end{tabular}

Taking the mean quantity of grammes corresponding to a single degree on other days, the increase of urea would correspond to a rise of $5^{\frac{1}{4}}$ in temperature. Thus, as far as the urea, \&c., are concerned, the fit was as severe as on previous days.

The urine was again collected hourly during the 14th.

Here the urea and chloride of sodium were again in great excess during the whole day, and also during the night previous.

\begin{tabular}{|c|c|c|c|}
\hline Hour. & Urea per hour. & $\begin{array}{l}\text { Chloride per } \\
\text { hour. }\end{array}$ & Water per hour. \\
\hline $\begin{array}{l}1.30 \text { p.m. to } 6 \text { a.m. } \\
6 \text { to } 7 \text { a.m. } \\
7 \text { to } 8 \text { a.m. } \\
8 \text { to } 9 \text { a.m. } \\
9 \text { to } 10.30 \text { a.m. } \\
10.30 \text { to } 11.30 \text { a.m. } \\
11.30 \text { a.m. to } 1.30 \text { p.m. } \\
1.30 \text { to } 3.30 \text { p.m. }\end{array}$ & $\begin{array}{l}1 \cdot 620 \\
2 \cdot 715 \\
1 \cdot 332 \\
2 \cdot 545 \\
1 \cdot 106 \\
1 \cdot 107 \\
1 \cdot 118 \\
1 \cdot 180\end{array}$ & $\begin{array}{l}0 \cdot 168 \\
0.585 \\
0.405 \\
0.877 \\
0.320 \\
0.421 \\
0.312 \\
0.254\end{array}$ & $\begin{aligned} & 85 \text { c.c. } \\
& 150 \text { c.c. } \\
& 90 \text { c.c. } \\
& 172 \text { c.c. } \\
& 67 \text { c.c. } \\
& 78 \text { c.c. } \\
& 60 \text { c.c. } \\
& 77 \text { c.c. }\end{aligned}$ \\
\hline
\end{tabular}


On the second and fourth hours the urea rose to nearly double the quantity of other hours. After the second rise it remained stationary for two hours, and then rose. This corresponds to some extent with the urea the day before; but after the second rise the fall was not so great, and the subsequent rise was very small in amount.

The chloride more closely resembled the day before. Like the urea of the same day, it rose twice, but the last rise exceeded the first, and was followed by a considerable fall, and this again by a rise of some extent, and then it again fell. The second rise and fall corresponding to the commencement of the sweating stage, the first fall probably would have corresponded (had the temperature risen) to an oscillation or a permanency at the termination of the period prior to the cold stage.

The water closely corresponded to the chloride.

Detracting 1.000 gramme from each hour, that being the necessary quantity to reduce the urea in the night urine to the amount normal to this man, and again, as on the day before, calculating what height the temperature would have reached had it risen, it is found to be $3^{\circ}$.

This fit was therefore less severe than that on the previous day. It thus appears that variations in the urea and chloride of sodium continue to occur at those periods when, if the fit had continued, the temperature would have risen. The same fact has been noted by Redenbacher; and it would show that the cure of the fit by quinine, in this man, was followed by a much larger excretion of urea during what would have been the apyrectic hours than had been noted at the corresponding time when he was suffering from the disease.

Case 2.-Tertian ague.-The following case of ague occurred in a boy, æt. 19, strong, and in every respect healthy with exception of the attack of ague. The boy had not been out of London for twelve months before, but at that time came over from Dantzig, having been there for some months. 
He was admitted into the hospital with the second fit, which was very slightly marked, the fit increasing subsequently in severity till he took four grains of quinine every two hours, which prevented its continuance. It was tertian in type.

Everything was conducted exactly after the manner of the former case. The urine, however, was collected (on one day only) by the stage, and not by the hour. His pulse was taken each quarter of an hour, with the temperature.

The two following charts of the temperature will be found to correspond closely with those given before, the correspondence holding mostly with the severer fits. In the first, the temperature rises slowly up to the cold stage; it then rises rapidly, running up continuously to the commencement of the hot stage, at which point it remains stationary for half an hour; it then runs up to its highest point, remains stationary for a short time, and sinks till the sweating stage commences, when, instead of oscillating, it remains stationary for half an hour, then falls and oscillates, but remains high even at 9 p.m., thus differing from the former and subsequent tables.

This further illustrates the slow rise of the stage previous to the cold one; then its rapid rise, the rise being here also greater than at any other period; also its tendency to be affected first at either termination as the fit becomes less severe. It shows that the temperature falls before the commencement of the sweating stage, and that at this point it either oscillates or remains stationary; and in the severe fit, that the temperature has a tendency to remain stationary at its highest point.

The next chart (that of April 4th) shows the temperature on the day the fit was severer, and consequently we find indications of this in the character and fall of the temperature. It shows at the commencement of the cold stage a tendency to be stationary, but after this it runs up continuously with no permanent period at the termination 
of the cold stage, though an approximation is seen in the rise at this point being less than the previous ones. It then remains permanent for some time, and then very slowly sinks, remaining permanent for half an hour just where the sweating commences; the temperature here also falling before the sweating stage commenced. Thus, the continuous rise, the permanency when at its height, and the slow and gradual fall, all indicate the severity of the fit, besides the great height to which the temperature reaches.

The urea, here only estimated for each stage, corresponds to the results before stated. Taking the average amount per hour in the sweating stage as the nearest approach to the quantity normal to the boy, it is found that there is an increase in the period previous to the fit; this continues increasing, is highest during the cold stage, then falls somewhat in the hot, and again falls still lower in the sweating.

The same is exactly the case with the chloride of sodium and water. ${ }^{2}$

The patient drank-

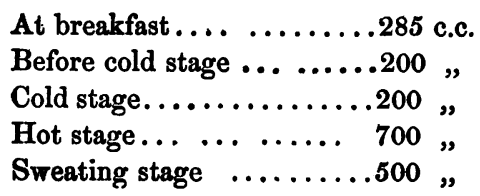

He passed the following quantity of urine :

$$
\begin{aligned}
& \text { Before fit ( } 3 \text { hours }) \ldots \ldots \ldots 162 \text { c.c. }=54 \text { c.c. per hour. } \\
& \text { Cold stage }(1 \text { hour }) \ldots \ldots \ldots 100, "=100 \\
& \text { Hot stage }(2 \text { hours }) \ldots \ldots \ldots 180, "=90 \\
& \text { Sweating stage }\left(4 \text { hours) } \ldots 150, "=37 \frac{1}{2} \quad "\right.
\end{aligned}
$$

1 The quantity of urea to each degree was 1.977 grm., showing a close correspondence to the amount for each degree in the former case. The correspondence would probably be closer still if the normal amount of this patient was reduced to that of the former.

2 The amount of chloride of sodium corresponding to each degree was 0.502 . 


\section{APRIL 2ND}

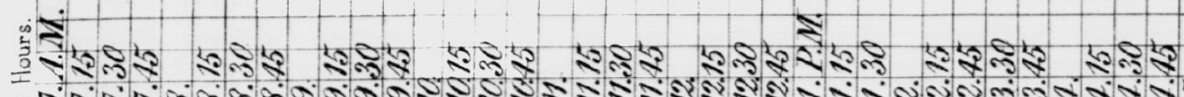

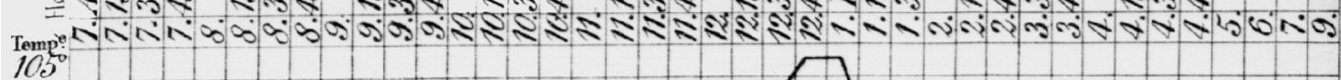
$4 / 5$
$3 / 5$
$2 / 5$
15
$104^{\circ}$

10

$103^{\circ}$

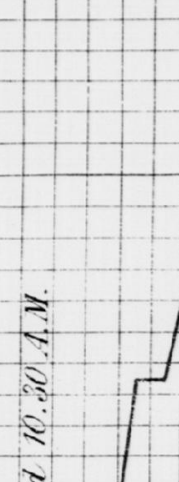

102

101

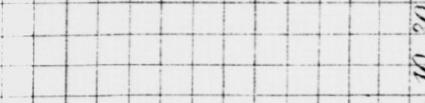

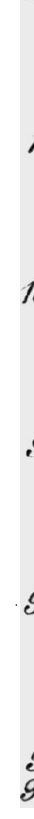

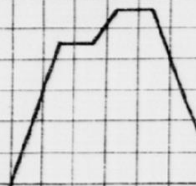




\section{APRIL 4TH}

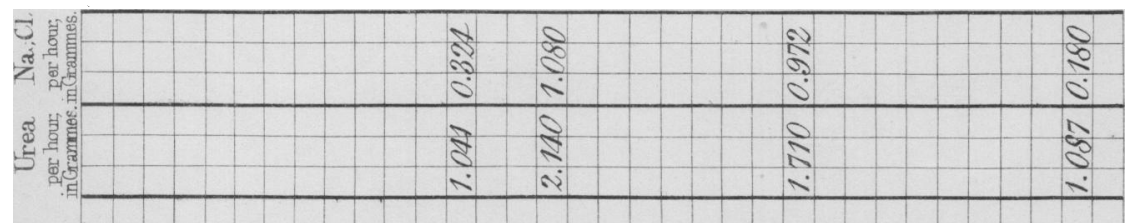

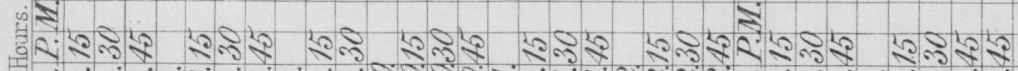
Temp $106^{\circ}$

$4 / 5$

$3 / 5$

$105^{\circ}$<smiles>C1CC1</smiles>

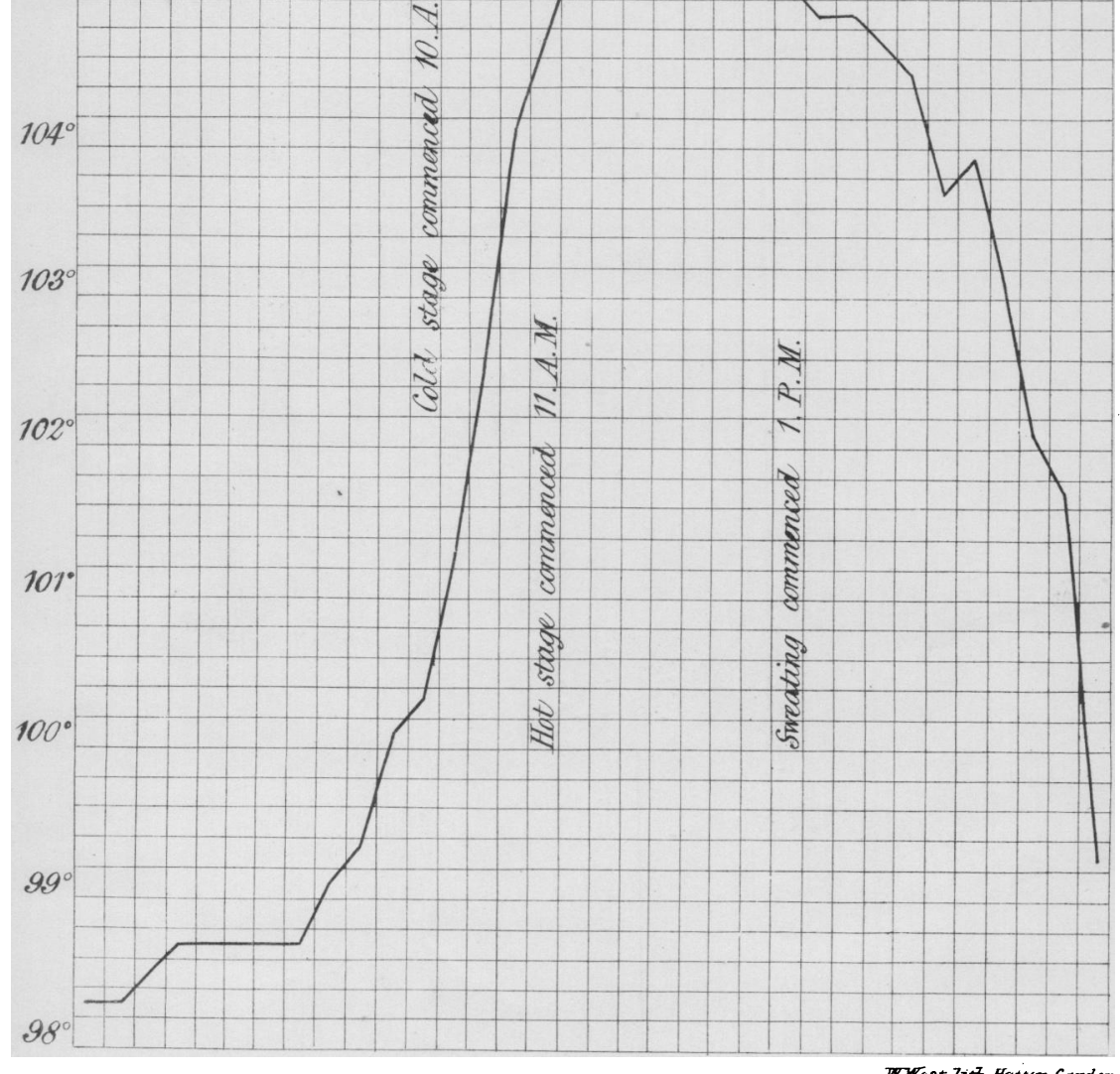


Pulse.

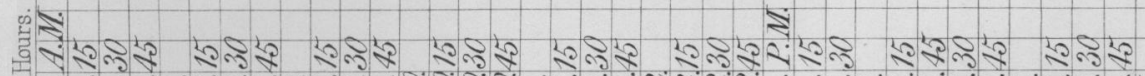
120

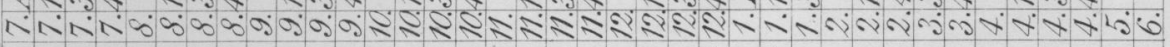
110

90

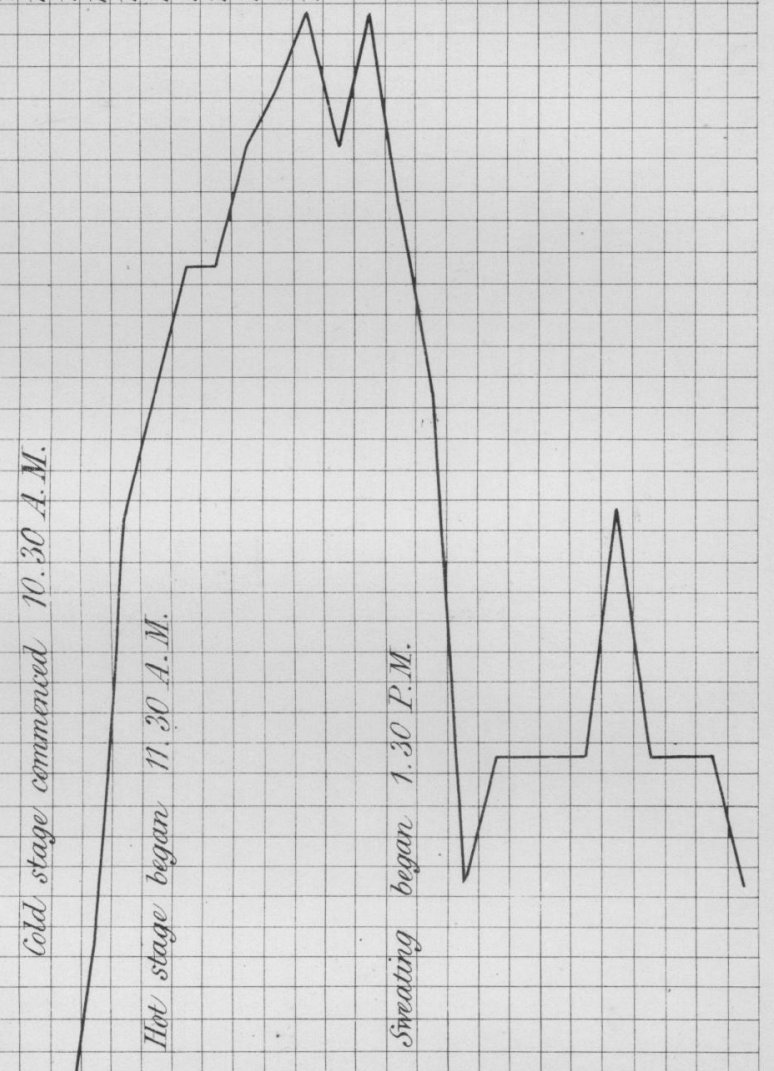

80

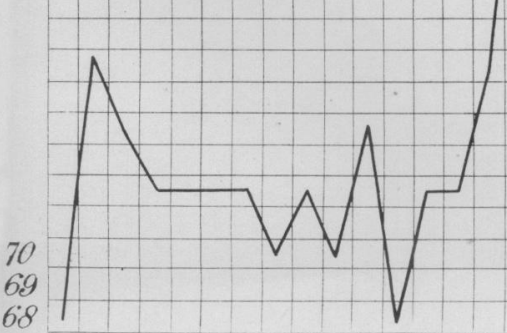




\section{APRIL 4 TH}

\section{Pulse.}

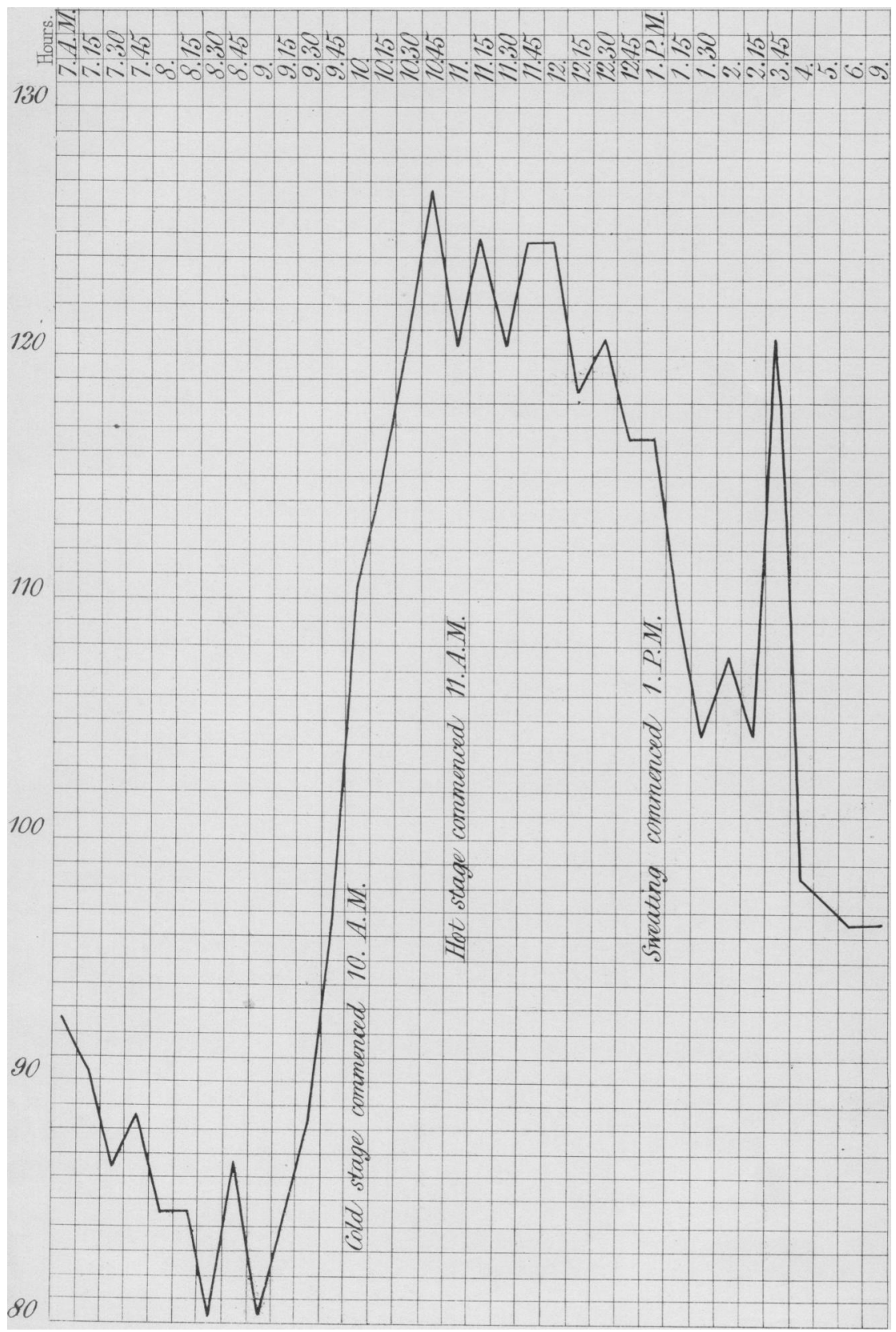


Thus, during the period before the cold stage he drank 323 c.c. in excess over the quantity of urine passed.

Cold stage, he drank 100 c.c. more than he passed;

$\begin{array}{llll}\text { Hot stage, } & 520, & \text { " } & \\ \text { Sweating, } & \quad 350 "\end{array}$

making a total of 1293 c.c. in excess of the total amount of urine voided. In this respect, again, he corresponds to the previous patient.

The pulse was taken every quarter of an hour with the temperature in the two fits, and the result is shown in the two following charts. In the first the pulse at the very commencement falls somewhat, and then oscillates. Just before the commencement of the cold stage it commences rising, and then remains stationary for half an hour; then runs up enormously and rapidly during the whole of the cold stage, and at its termination remains again stationary for half an hour; then runs up slightly, oscillates when it has reached its highest point, and immediately on the sweating stage setting in it falls rapidly. In the second chart, at the very commencement, the tem. perature falls more than it did in the previous one; in the stage previous to the cold it rises more rapidly than in the previous one; runs up still more rapidly during the cold stage, reaches its highest point, and then immediately oscillating, before the sweating stage commences; after oscillating for some time, it falls, and at the commencement of the sweating stage it stands stationary for half an hour, and then falls greatly. During the entire rise there is no tendency for it to remain stationary, still less to oscillate.

This last fit was more severe than the former.

Thus, on both days the pulse commences by falling somewhat, then on both it rises before the fit commences, thus corresponding to the urine and its constituents and also to the temperature. At the commencement of the cold stage, in the less severe fit, the pulse remained stationary for half an hour, and again at the termination of the same stage, whilst nothing of this is seen in the severer one, thus cor- 
responding to the temperature, \&c. Again, on reaching the climax on both days the pulse oscillates, and the temperature also was unsteady at the same time, though to a much less extent. The pulse commences falling before the sweating stage, and then falls rapidly, more so than the temperature. The pulse, however, fell most rapidly in the less severe case.

Thus, a close correspondence exists between the pulse and the temperature. Like it, the character of the rise varies with the intensity of the fit; it rises before the cold stage commences; then, if the fit is not very severe, remains stationary; again rises through the entire cold stage, the rise being more considerable than during any other period; then falls before the sweating stage, and just at the commencement of this stage stands still for half an hour in the severer cases, and falls subsequently slower than in the less severe cases, in which also there is no stationary period.

Case 3.-A case of hectic fever.-The following wellmarked case of hectic is subjoined, on account of its close correspondence to the cases above given.

It occurred in a phthisical patient, æt. 45, under Dr. Walshe. It was particularly obstinate in resisting all measures for its removal, and was also peculiar in its occurring always during the day, and its very long continuance, as it commenced at 7 a.m., and continued to 5 p.m. All the stages were unusually well marked, consisting in severe rigors, accompanied with great pain about the loins and legs, the rigors coming on gradually, the sensation of cold being first observed about the feet; the hot and especially the sweating stages followed regularly. The observations were conducted in all respects after the manner of those already detailed.

\section{Temperature.}

Here, as in the other cases, the temperature began to rise before the rigors set in, ran up slowly through the 


\section{Case of Hectic.}

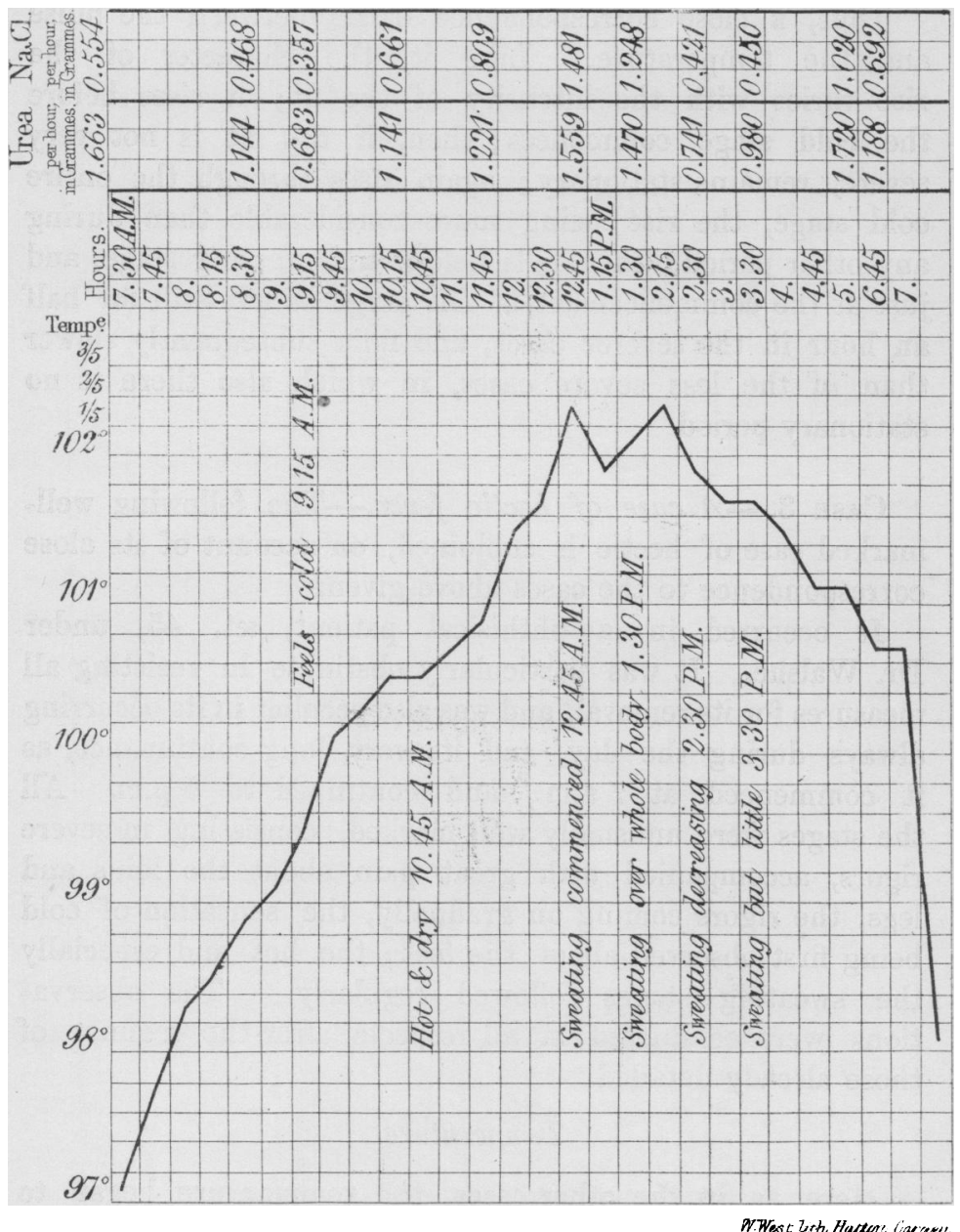


whole of the cold stage, at its termination remained stationary for half an hour, then again ran up slowly, remaining stationary once, till it reached its highest point, when it oscillated, the rise in the oscillation occupying half an hour, then slowly and gradually fell, every now and then remaining stationary. A close connexion exists between this temperature and those given formerly; the rise, however, before the shivering set in was peculiarly great, and the cold stage very short, the rise in this stage not being so much in excess over the other stages as in the cases of ague.

\section{Urea.}

Unlike the cases of ague, the urea falls during the period preceding the rigors, and reaches its minimum immediately they set in; the quantity then rises rapidly, and becomes greatest during the hour immediately preceding the sweating stage. The quantity then falls rapidly through the sweating stage, reaching its minimum when the sweating is most severe; then rises again even higher than it was during the hot stage, and after that falls to its normal amount.

\section{Chloride of sodium.}

This corresponds to the urea in all respects, except that the rise at the termination of the fit does not equal the amount secreted during the hot stage.

\section{Water}

Again corresponds to both the above, except that its greatest quantity was poured out an hour later than the greatest amount of urea and chloride of sodium (showing the independence of these substances one of the other).

The patient was permitted to drink ad libitum; the quantity, however, was not measured. 
The following table shows the variations in the amount of urinary water :

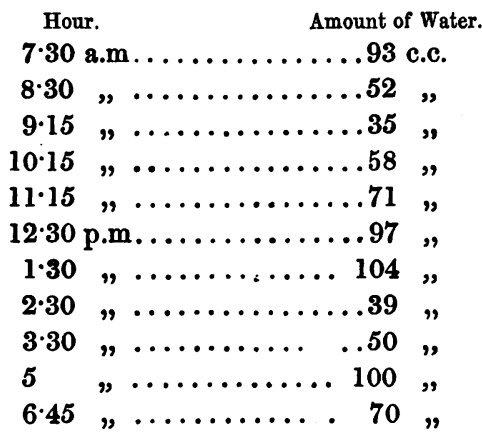

The pulse in this patient remained about 80 throughout the day.

\section{General Conchusions.}

The following are the conclusions deducible from the facts noted in the cases of ague.

\section{Temperature.}

1. This rises before the commencement of the subjective fit.

2. The time before the cold stage at which the rise commences varies.

3. It continues to rise during the entire cold stage.

4. The rise during this stage is greater than during any other.

5. It reaches its highest point during the hot stage, but falls again before the sweating stage, the fall being gradual.

6. The fall is more rapid during the sweating stage. The rapidity is in proportion to the slightness of the fit.

7. Definite variations occur in the rise and fall of the temperature indicative of alterations in the severity of the fit.

8. These variations first appear at the commencement and termination of the cold stage.

9. Their earliest indication is seen in a tendency for the later rises in the cold stage to become less extensive. 
10. The temperature next becomes stationary for a variable time at either or both extremities of the cold stage.

11. Should the fit become still less severe, the temperature oscillates at these points.

12. An oscillation in the middle of the cold stage indicates a still further diminution in the severity of the fit.

13. Variations also occur during the hot stage.

14. In the severest fits there is a tendency for the temperature to remain stationary at its highest point.

15. If less severe, the temperature immediately falls on reaching its extreme height.

16. When the fits become still less severe the temperature next fails to reach to such a height as previously; but at this point again has a tendency to be stationary.

17. Should the severity of the fit be still less, it just touches the extreme point, and immediately falls.

18. Variations are also observed during the fall of the temperature.

19. Thus, at the junction of the hot and sweating stage, an oscillation, or a tendency to remain permanent, always occurs.

20. In continuing to fall, the temperature either falls gradually and continuously; this occurs in the severe fitor,

21. Remains stationary every now and then; this indicates a somewhat less intensity of the fit-or,

22. It oscillates; this accompanies the most rapid fall, and occurs during the least severe fit.

23. After sinking to its extreme point, the temperature has a tendency to rise again, the rise being often considerable.

Urea, Chloride of Sodium, and Water.

24. The urea, chloride of sodium, and water, also begin to increase in quantity before the commencement of the cold stage.

25. They continue to rise rapidly, and become most 
abundant either at the termination of the cold or the commencement of the hot stage.

26. These urinary constituents commence to fall in amount before the temperature reaches its highest point.

27. During the latter part of the hot stage they decrease in amount slowly.

28. They fall rapidly during the sweating stage, the rapidity of the fall being proportionate to the slightness of the fit.

29. These constituents exhibit variations corresponding to the variations in the temperature.

30. Thus, when the temperature remains stationary at either end of the cold stage, these urinary constituents also remain stationary, or fall somewhat. When the temperature oscillates, the fall in these constituents is proportionately greater.

31. A fall occurs in these constituents corresponding to the oscillation in the temperature at the termination of the hot stage, the fall in their amount corresponding to the depth of the oscillation.

32. A greater diminution in the amount of these constituents is observed when an oscillation occurs, than when the temperature decreases gradually, or tends to remain stationary.

33. The increase in the urea and water is definite, the same amount of increase corresponding to a single degree each day.

34. A greater increase in these constituents corresponds to a single degree at a high than at a low temperature.

35. No connexion existed between the various rises of the urea and chloride of sodium when equal periods were compared together.

36. The urea appeared to be independent entirely of the influence of the amount of water.

37. The chloride of sodium also underwent a definite increase, but this increased per-centage remained the same whatever the amount of water was, so that the total amount of chloride was greatly under the influence of the urinary water. 
38. The chloride rose steadily and constantly, and did not observe the variations corresponding to temperature which were seen in the urea, but the water varying with the urea and influencing the chloride, as seen above, caused similar variations in the hourly amount of the chloride.

39. The quantity of water drunk in no way influenced the total amount excreted.

40. The increase in the above constituents often commenced before a corresponding rise in the temperature occurred.

41. The variations in the temperature above described often followed similar variations in the urea, but never preceded them.

42. Quinine given in a single, but large dose, when the temperature commenced to rise, lowered the temperature and postponed the fit for an hour, but had no other effect on that fit, though it prevented its recurrence next day, another scruple having been taken.

43. The pulse corresponded closely with the temperature. 